
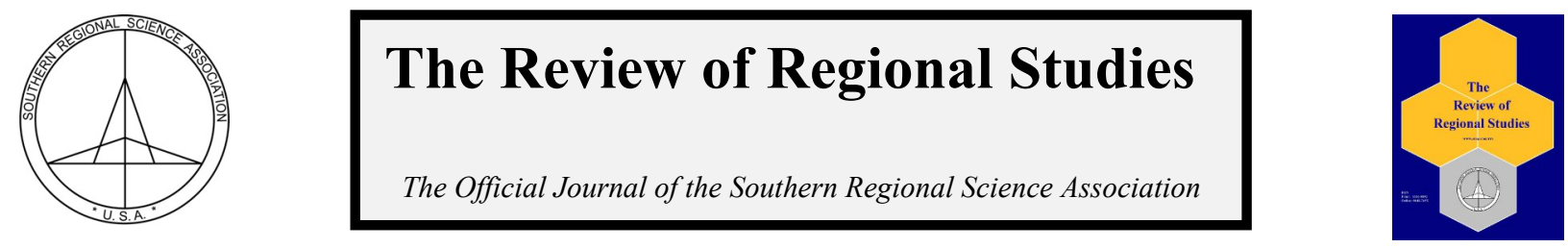

\title{
A Typology of Rural Airports in the United States: Evaluating Network Accessibility
}

\author{
Fangwu Wei ${ }^{\mathrm{a}}$ and Tony H. Grubesic ${ }^{\mathrm{b}}$ \\ ${ }^{a}$ Center for Spatial Analytics and Geocomputation,Drexel University, USA \\ ${ }^{b}$ Center for Spatial Reasoning \& Policy Analytics, Arizona State University, USA
}

\begin{abstract}
Since deregulation of the airline industry in 1978, carriers have largely focused their commercial service efforts on medium and large hub airports located in metropolitan areas with sufficient demand for air travel services. These profitable locations often cross-subsidize service to smaller hubs, which can function as feeder nodes/links to the larger hub-to-hub carrier network. However, as fuel and labor costs continue to increase for commercial carriers, reductions and terminations of air service in smaller rural markets are common, reducing carrier footprints and leaving many regions of the United States without viable air transport options. To be clear, this is not a new development. Many rural and remote airports are all too familiar with service reductions, which is why safeguards such as the Essential Air Service program continue to operate. The purpose of this paper is to explore the network and geographic context of airports in the U.S., evaluating relative accessibility and using this information to develop a typology of rural airports for the U.S. Implications for policy and transportation planning are discussed.
\end{abstract}

Keywords: transportation, rural airport, network, typology, planning

JEL Codes: L93, L98

\section{INTRODUCTION}

Since deregulation of the airline industry in 1978, commercial carriers have largely focused their service efforts on medium and large hub airports located in metropolitan areas with sufficient demand for air travel. These large, profitable locations often cross-subsidize service to smaller, feeder airports, which collect passengers for routing through larger hubs. However, due to a variety of external and internal factors that affect the airline industry, including economic recessions, high fuel costs, and mergers and acquisitions between carriers, reductions and terminations of air service in smaller rural markets are common. For example, between 2007 and 2012, domestic service at the largest 29 U.S. airports declined 8.2 percent. During the same timeframe, however, service at smaller U.S. airports declined by 21.7 percent (Wittman and Swelbar, 2013). To be clear, this is not a new development. Many rural and remote airports are all too familiar with service reductions. Currently, there are two programs to help small communities maintain their air services in the U.S. The first is a federally subsidized program known as Essential Air Service (EAS) (Grubesic and Wei, 2013; Grubesic et al., 2014). EAS was initially structured to help rural and remote airports offset the exodus of carriers to larger and more lucrative markets after deregulation of the airline industry in the United States in 1978 (Grubesic

Wei is a Research Assistant at the Center for Spatial Analytics and Geocomputation, College of Computing \& Informatics, Drexel University, USA. Grubesic is Professor and Director of the Center for Spatial Reasoning \& Policy Analytics, College of Public Service \& Community Solutions, Arizona State University, USA. Corresponding Author: T. H. Grubesic E-mail: grubesic@asu.edu 
and Matisziw, 2011). As of June 2014, there are 117 active EAS communities, and in each location, several commercial flights are provided each day to nearby medium or large commercial hubs. For example, Worland, Wyoming (WRL), ${ }^{1}$ is served by Great Lakes Airlines with a 19-seat Beechcraft 1900 that provides connecting service to Denver, Colorado (DEN). ${ }^{2}$ The second program, the Small Community Air Service Development Program (SCASDP) established by the Wendell H. Ford Aviation Investment and Reform Act for the $21^{\text {st }}$ Century (P.L. 106-181) and reauthorized by the Vision 100-Century of Aviation Reauthorization Act (P.L. 108-176) (USDOT, 2013a), allows smaller airports to apply for federal monies that can be used to mitigate identified service deficiencies (USDOT, 2013b). During fiscal year 2013, SCASDP awarded 25 grants totaling $\$ 11.4$ million. As detailed by Wittman (2014), the primary purpose of these awards is to fund new service, although grants have been used to launch local and regional marketing efforts, terminal improvements, and parking expansion (USDOT, 2013b).

Although these types of marketing and infrastructure improvement efforts are certainly important to the long-term vitality of small and rural air transport gateways, one key challenge that nearly all of these airports face is a lack of accessibility. The reason that the accessibility of rural airports is so important is twofold. First, there are noteworthy tradeoffs for passengers when selecting rural airports as their gateway to the commercial air transport network. When compared to most small, medium, and large hubs, passengers flying out of rural airports are often forced to accept an additional connection (or two) when taking a trip. This means more time spent sitting at airports (waiting for connections to arrive), a higher probability for delays (because of multiple connections), and more time spent flying between intermediate locations before the final destination is reached. Second, service frequency from rural airports is relatively low when compared to larger hubs. For example, carriers participating in the EAS program are required to offer a minimum level of service between rural communities and their assigned medium or large hub. ${ }^{3}$ The Merced, California, airport (MCE), for instance, offers 13 weekly roundtrip flights to Los Angeles, California (LAX). This is a severely reduced palette of destinations and associated flight frequencies when compared to the neighboring Fresno, California (FYI), which offers nonstop service to multiple locales such as Honolulu, Hawaii (HNL); Dallas/Fort Worth, Texas (DFW); Portland, Oregon (PDX); Las Vegas, Nevada (LAS); Seattle, Washington (SEA); and many others. Clearly, the accessibility of rural airports affects their viability as travel options for many passengers (Matisziw and Grubesic, 2010), but it also may have more severe economic effects for regions (Allroggen and Malina, 2014; van den Heuvel et al., 2014).

Given the somewhat tenuous nature of commercial air transport in rural locations, particularly with respect to accessibility, the purpose of this paper is to explore the network and geographic context of airports in the United States, evaluating relative accessibility and using this information to develop a typology of rural airports for the United States. Further, this exploratory analysis is structured to provide meaningful, empirical evidence to improve rural transportation strategies, highlight the significant gaps in rural accessibility and illustrate the implications of these gaps for rural communities and their airports.

\footnotetext{
${ }^{1}$ The terminology used for referencing specific airports in this paper relies on a combination of city and state references, mixed with IATA codes when appropriate. IATA codes are an essential component of the travel industry. Not only do they help identify airports, hundreds of electronic applications are built upon the IATA codes and help make passenger and cargo operations more efficient (IATA, 2014).

${ }^{2}$ Great Lakes Airlines is provided $\$ 1,987,148$ in subsidies by the EAS program to serve this route.

${ }^{3}$ It is important to emphasize here that carriers never offer more service than the minimum requirement. There is no financial incentive to do so for EAS routes.
} 


\section{BACKGROUND}

\subsection{Rural Airports and "Pockets of Pain"}

Deepening our understanding of rural transportation challenges, particularly for commercial air transport, requires a clear framework for measuring rurality and classifying rural airports (Isserman, 2005). In the United States, rurality can be defined in several ways. Consider the typology provided by the U.S. Census Bureau for urban and rural areas: 1) urbanized areas (UAs) correspond to areas of 50,000 or more residents and 2) urban clusters (UCs) represent regions with at least 2,500 residents, but less than 50,000. To clarify, UAs and UCs form the urban cores of metropolitan statistical areas (MSA) and micropolitan statistical areas ( $\mu$ SA), respectively (U.S. Census, 2010). Specifically, each MSA will contain a UA of 50,000 residents or more. Each $\mu \mathrm{SA}$ contains at least one UC of at least 10,000 residents, but less than 50,000. Rural areas encompass all population and territory not included within a UA or UC (Federal Register, 2012).

To make matters more confusing, the Bureau of Transportation Statistics (BTS) compiles an annual list of rural airports for the Internal Revenue Service (IRS). This list is purportedly used by commercial carriers for establishing air fares (U.S. Department of Transportation, 2013c). Specifically, travel to and from airports defined as rural benefits from reduced ad valorem ticket taxes ${ }^{4}$ and is exempt from segment fees (U.S. Department of Transportation, 2013c). These reductions in taxes and fees stem from the Taxpayer Relief Act of 1997. The 2013 IRS definition for "rural airport" is any airport that has fewer than 100,000 commercial passengers departing from the airport by air during the second preceding calendar year ${ }^{5}$ and adheres to at least one of the following criteria: 1) The airport is not located within 75 miles of another airport from which 100,000 or more commercial passengers departed during the second preceding calendar year, ${ }^{6}$ ) the airport was receiving EAS subsidies as of August 5, 1997, or 3) the airport is not connected by paved roads to another airport. The most recent rural airport list provided by the USDOT to the IRS is published online (http://tinyurl.com/p6w667x) and contains 3,661 entries, the bulk of which (80 percent) do not maintain an IATA identifier code. Figure 1 displays all 719 U.S. rural airports with IATA identifier codes. It is important to note that the majority of these airports do not currently provide commercial service. Instead, most serve as public gateways for private aircraft, agricultural operations (e.g., spraying crops), or small freight/logistics hubs for a region.

A second facet of rural air transport that needs elaboration is the role that commercial air service plays in small and geographically isolated communities. The vitality of rural locales is strongly linked to the availability of air transport because it maintains and enhances economic development opportunities (Vowles, 1999; Brueckner, 2003; Graham, 2008; Percoco, 2010; Button and Yuan, 2013; Grubesic and Wei, 2013; Grubesic et al., 2014). The accessibility of a community or a region is critically important to local economic growth and development (Keeble et al., 1982; Keane, 1984; Johansson, 1993). Further, air travel provides high speed options to members of the private sector (corporations and individuals) in smaller communities that require enhanced levels of face-to-face communications (Kanafani and Abbas, 1987; Reynolds-Feighan,

\footnotetext{
${ }^{4}$ The current ad valorem tax is 7.5 percent of the ticket price (FAA, 2013).

${ }^{5}$ Second preceding calendar year is defined as two calendar years prior to the year in question.

${ }^{6}$ Airport distances are calculated from a start and end latitude and longitude based on a constant compass course for a rhumb line between the points (loxodrome) using an Albers Equal Area Projection (IRS, 2013).
} 
1995). For example, Debbage (1999) identifies a strong connection between "air passenger volume and air service connectivity" and "administrative and auxiliary employment" at airports in the Carolinas. In addition, there is a positive relationship between knowledge-based economic activities (e.g., information technology, biotechnology, electronics, and management services) and local air travel (Button and Taylor, 2000). As detailed by Rasker et al. (2009), this is particularly true in the western portions of the United States, where enormous expanses of public lands are not available for development. This means that the distances between urban centers, towns and other communities are much larger, reinforcing the need for air transport to help get products to market and lubricate the movement of residents participating in knowledge-based professions (Drucker, 1994; Mathur and Stein, 2005).

Historically, rural air transport options and associated levels of service have been a function of local market size, the geographic proximity of larger hubs, and the proximity of natural amenities (i.e., resort areas) or major military facilities (Goff, 2005). Simply put, there is heterogeneity in commercial air service to rural locales. However, as noted previously, deregulation prompted fears that massive service reductions would take place in rural communities because commercial carriers would shift their focus to more profitable markets and larger metropolitan areas (Flynn and Ratick, 1988; Matisziw and Grubesic, 2010). Again, this is the primary reason that the Essential Air Service program was established (Matisziw et al., 2012).

\section{Figure 1: The Spatial Distribution of All Rural Airports with IATA Codes in the United States, 2013}

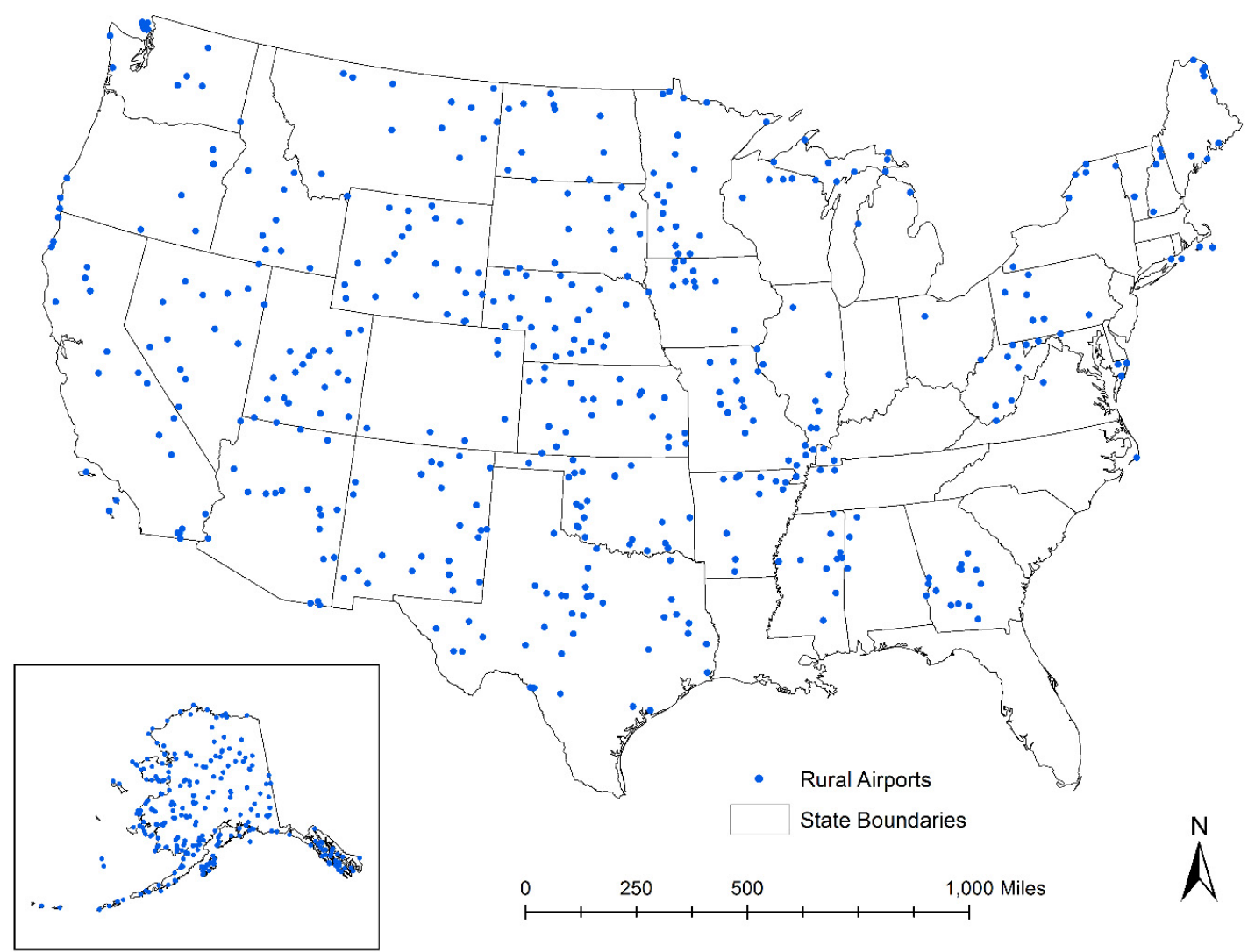

(C) Southern Regional Science Association 2015. 
Within the context of EAS, it is important to note that the program and its participating communities are somewhat dynamic. Subsidy levels vary on an annual basis and a handful of airports come and go in the program. Regardless of this dynamism, many problems remain, including the overall efficiency of the EAS program (Grubesic et al., 2014). Not only do EAS airports cannibalize their own markets (Grubesic and Matisziw, 2011), they are frequently located near relatively vibrant small hubs (as defined by the FCC), which offer a more robust range of air transport services, but are not considered in the EAS community eligibility criteria (Grubesic and Wei, 2013; Grubesic et al., 2012). In short, there is room for improvement in the EAS system and the rural air transport network, more generally.

From a broader, policy-oriented perspective, Goetz and Vowles (2009) note that thirty years after deregulation the results for the U.S. commercial air transport industry are somewhat mixed. Although deregulation prompted higher levels of service frequency to the most popular destinations and lowered the associated fares (on average), deregulation also increased financial instability within the industry by reducing quality of service, increased passenger fees (e.g., checked baggage, selection of seat), and accelerated changes in network configurations via hubbing, dehubbing, mergers and acquisitions (Goetz and Vowles, 2009). In sum, this process has "squeezed" service to and from smaller communities through schedule reductions and higher fares, creating "pockets of pain" in the air transport landscape (Goetz, 2002). These types of high-fare, low service conditions can emerge when a large carrier dominates the local market and practices predatory pricing as a strategy for eliminating competition from low cost carriers (LCCs) or generates entry barriers for competition in local markets through exorbitant gate lease fees (Shaw and Ivy, 1994; Goetz and Sutton, 1997; Vowles, 2000; Goetz, 2002; Grubesic and Zook, 2007; Goetz and Vowles, 2009). At the time Goetz (2002) conducted his empirical work, notable pockets of pain existed in the southeastern U.S., including airports such as Columbia, South Carolina (CAE); Memphis, Tennesee (MEM); Montgomery, Alabama (MGM); and Mobile, Alabama (MOB), extending northward to Cincinnati, Ohio (CVG), and select airports in New England and the upper Midwest. That said, these results are over a decade old and these patterns have shifted. For more recent work on hubs, airfare pricing and perspectives for markets outside North America, see (Grubesic and Zook, 2007; Hazledine, 2011; Gillen and Hazledine, 2011; Zhang et al., 2013).

\subsection{Accessibility, Connectivity, and Airport Typology}

A third major facet that needs to be considered when establishing the contextual nature of commercial air transport in rural areas of the United States (and elsewhere) is the topological structure of airline networks (Zook and Brunn, 2006; Grubesic et al., 2008; Redondi et al., 2013; Grubesic and Matisziw, 2012; Wang et al., 2014) and its associated impacts on the connectivity and accessibility of local airports. From a pragmatic perspective, the effects of airline network structure manifest at the nodes, which serve as the access points to the system. Efforts to disentangle network topology, connectivity, and accessibility often result in the generation of airport typologies, which are useful for summarizing the wide variety of attributes found between airports. These range from simple typologies used by the Federal Aviation Administration (FAA), which categorizes airports by passenger enplanements (FAA, 2012) to more complex schemes that utilize nonhierarchical clustering approaches (Murray and Grubesic, 2002) to classify airports based on itinerary pricing, flight duration, connections, and routing data (Grubesic and Zook, 2007). Airport typologies can also be identified using alternative analytical approaches such as the Nystuen-Dacey (1961) method (Grubesic et al., 2008, 2009) and graph- 
theoretic or statistical network-based approaches geared toward identifying hierarchies between airports and geographical regions (Reed, 1970; Wacht, 1974; Nader, 1981; Chou, 1993; Shaw and Ivy, 1994; Bania et al., 1998; Bowen, 2000; Zook and Brunn, 2006; Grubesic and Zook, 2007; Reynolds-Feighan, 2007). For example, Guimerà et al. (2005) analyze the worldwide air transportation network and categorize airports with seven different roles: four roles for non-hub airports ("ultraperipheral nodes," "peripheral nodes," "nonhub connector nodes," and "nonhub kinless nodes") and three roles for hubs ("provincial hubs," "connector hubs," and "kinless hubs"). Additional layers of context, such as geopolitical factors, can also be taken into consideration when evaluating network community structure (Guimerà et al., 2005). Other examples include the work of Derudder et al. (2007), who examine U.S. cities and their place within the world city network in terms of global origins and destinations of airline passengers. Their results suggest a close relationship between hierarchy and regionality. In short, less important cities maintained fewer flight connections with globally important locales. Instead, they typically maintained a connection to one or two larger airports, with the remainder of their connections occurring between regional peers. This type of relationship often manifests in "huband-spoke" systems (O'Kelly, 1998; Grubesic and Zook, 2007). However, because the airline industry is so dynamic, it is important to remember that topologies are in constant flux, changing through time and across geography (Grubesic et al., 2009). Therefore, it is both important and necessary to occasionally re-examine the current state of airline networks, airport connectivity and system accessibility for evaluating transport policies.

Finally, it is important to reiterate the difference between access and accessibility for transportation studies. As noted by Geurs and Van Wee (2004, p. 28), accessibility is "the extent to which land use and transport systems enable (groups of) individuals to reach activities or destinations by means of a (combination of) transport mode(s), "whereas access refers to the opportunity (and level of effort) associated with entering a transportation system (Ellis et al., 1974; Demetsky and Korf, 1980). Airport accessibility studies include the work of Chou (1993), who uses first- and second-order nodal accessibility measures combined with regression analyses to evaluate the impact of airline deregulation on airport accessibility. Reynolds-Feighan and McLay (2006) measure accessibility of European airports by examining seat inventories, assigning weights and then ranking airports based on available seats and/or seat miles using a specialization ratio that compares the amount of traffic at a specific airport versus the amount of traffic at the busiest airport. Finally, Matisziw and Grubesic (2010) take this a step further by developing a mathematical model that evaluates both access to an airport and accessibility within the air transport network once passengers enter the system.

In sum, rural airports and their associated communities often face a wide array of contextual challenges for obtaining adequate transportation services. These challenges include the lack of spatial proximity to larger population centers, poor physical connections to terrestrial transportation systems (e.g., road and rail), and weak demand-side markets for air transport. ${ }^{7}$ Although many rural airports survive on freight traffic and associated demand from the agricultural sector, geographic isolation, poor physical connections to the terrestrial network and the air transport system can impede regional economic development for rural communities where small airports are located. This significantly weakens the ability of such communities to attract and hold commercial air service. Matters are further complicated by the operational challenges

\footnotetext{
${ }^{7}$ Markets with low demand, especially rural ones, remain a challenge because enplanements suffer, even when the frequency of service remains relatively high.
} 
associated with providing service in rural and remote locations, which include higher than average operating costs and diseconomies of scale.

In the next section, we outline the data and methods used for exploring the heterogeneities in the network and geographic context of rural airports in the U.S. and evaluate their relative accessibility to the larger commercial system at the regional and national level. This is followed by the presentation of empirical results and a discussion regarding the implications of rurality for air transport planning and policy.

\section{DATA AND METHODS}

\subsection{Airline and Airport Data}

The Airline Origin and Destination Survey (DB1B) database is a 10 percent sample of airline tickets from reporting carriers provided by the Bureau of Transportation Statistics (BTS, 2013). Although these data are sampled, records are structured as individual flight segments. As a result, the information associated with each flight is highly accurate, as are the aggregate statistics generated from the DB1B database. The DB1B database includes three datasets: DB1BCoupon, DB1BMarket, and DB1BTicket (Table 1.). Since the DB1BMarket dataset is the primary source for records on air traffic flow attributes, including origins and destinations, number of passengers, a code that identifies number of steps connecting two airports (e.g. PHL:DEN:PDX), and market fare information that can be used to capture itinerary cost, it is selected as the primary data source for analysis. For the purposes of this paper, air-traffic flow data for 2013 were obtained from DB1BMarket dataset and a total of 22,568,569 flights were retrieved.

Airport data were obtained from the National Transportation Atlas (BTS, 2011). This dataset includes locations of all public airports in the U.S. Information for classifying EAS airports in the contiguous U.S. (November 2013) was also collected from the USDOT (2013d), as were data for airports that received SCASDP funds between 2011 and 2013 (U.S. Department of Transportation, 2013b). Based on the rural airport classification data obtained from the IRS (2013), the lists of EAS/SCASDP airports, and the typology provided by the U.S. Census Bureau for urban and rural areas, a complete list of rural airports $(n=177)$ with commercial air service was structured for 2013 .

Table 1: Airline Origin and Destination Survey (DB1B)

\begin{tabular}{lll}
\hline \hline Data Table & Description & Important Fields \\
\hline DB1BCoupon & $\begin{array}{l}\text { Providing coupon-specific information } \\
\text { for each domestic itinerary of the Origin } \\
\text { and Destination Survey }\end{array}$ & $\begin{array}{l}\text { Origin and destination airports, } \\
\text { number of passengers, coupon } \\
\text { type, fare class, and distance }\end{array}$ \\
DB1BMarket & $\begin{array}{l}\text { Containing directional market } \\
\text { characteristics of each domestic itinerary } \\
\text { of the Origin and Destination Survey }\end{array}$ & $\begin{array}{l}\text { Origin and destination airports, } \\
\text { number of passengers, prorated } \\
\text { market fare, and airport group }\end{array}$ \\
DB1BTicket & $\begin{array}{l}\text { Containing summary characteristics of } \\
\text { each domestic itinerary on the Origin } \\
\text { and Destination Survey }\end{array}$ & $\begin{array}{l}\text { Itinerary fare, number of } \\
\text { passengers, origin airports, and } \\
\text { roundtrip indicator }\end{array}$ \\
\hline \hline
\end{tabular}




\subsection{Network Analysis}

A suite of graph-theoretic, network, and statistical methods are used for exploring the commercial air transport system for the United States in this paper. The graph-theoretic methods include the use of a simple dispersion measure for the network, known as the Shimbel Index $(D)$, which represents the sum of all shortest paths between each city pair, $d_{i j}{ }^{8}$ :

$$
\text { (1) } D(V)=\sum_{i=1}^{N} \sum_{j=1}^{N} d_{i j}
$$

where the shortest path between node pairs is measured by the number of intervening arcs between an origin and destination pair. For this particular measure, smaller row sums $\left(D_{i}=\right.$ $\sum_{j} d_{i j}$ ) suggest that airports/communities are more accessible or have an efficient set of connections to the commercial air transport network in the U.S. Conversely, larger row sums suggest that more effort is needed to travel between cities and indicate a less efficient set of connections between origin/destination $(\mathrm{O} / \mathrm{D})$ pairs.

Several measures of centrality (Freeman, 1979) are also used to capture the characteristics of airports within the system. For instance, one popular and widely used measure of centrality leveraged in this paper is the degree of node, $\delta$. Given a matrix of destinations from a particular airport, $A$, with elements $\left\{A_{i j}\right\}$, the degree of node is obtained by summing the total number of destinations served from node $i$ :

$$
\text { (2) } \delta=\sum_{j=1}^{N} A_{i j}
$$

where higher degree nodes often exhibit more relevance to network operations. This often occurs when airports function as hubs, important gateways or as popular origin/destination locations (Fleming and Hayuth, 1994; Grubesic and Matisziw, 2012).

A second measure of centrality uses shortest-path information to evaluate the probability that some type of interaction between an origin and destination will include a particular node (e.g. hub). For this particular measure, it is assumed that one of the shortest paths will be used in connecting the O/D pair. If there is more than one shortest path, it is assumed that there is an equal probability that each will be used. Therefore, if $m_{i j k}$ represents the number of shortest paths linking airports $i$ and $j$ involving airport $k, \sum_{k} m_{i j k}$ captures the total number of shortest paths linking each origin and destination that involves airport $k$. As detailed by Grubesic et al. (2008), the probability that one of these paths is used can be represented by the function, $1 / \sum_{k} m_{i j k}$. Further, given this probability function, the relative centrality of each node for all of the shortest paths can then be measured as:

$$
\text { (3) } C B_{k}=\sum_{i} \sum_{j} \frac{m_{i j k}}{\sum_{k} m_{i j k}} i \neq j \neq k \text {. }
$$

The minimum value for an airport is 0 and occurs if $k$ does not participate in any of the calculated shortest paths. It is also important to remember that this measure of betweenness is sensitive to network size. Hence, Freeman (1979) suggests the use of a standardized measure to mitigate bias.

Finally, closeness centrality (Freeman, 1979) is a relatively intuitive measure that also utilizes shortest path information to capture the relative network proximity of an airport to all

${ }^{8}$ If $i=j, d_{i j}=0$. If a pair of airports indicates a direct flight, $d_{i j}$ will be 1 regardless of how close two airports are. 
other airports. Simply put, the more central an airport is to the network, the lower its total distance to all other nodes. Thus, closeness can be captured as follows:

$$
\text { (4) } \varphi=\sum_{j} \frac{1}{d_{i j}} \text {. }
$$

Much like the betweenness centrality measure, the normalized closeness scores range between 0 and 1 . If an airport receives a score of 0 , it is completely isolated from the system, if an airport receives a score of 1 , it is directly connected to all other airports in the system.

\subsection{Cluster Analysis}

A fuzzy clustering approach is used to synthesize collected air flow attributes from the DB1B database and the network centrality measures specified previously to develop a typology of rural airports. The primary reason that a fuzzy-based approach makes sense for this application is that the resulting clusters do not adhere to an all-or-nothing assignment structure for membership. Instead, fuzzy clusters allow observations to maintain a probabilistic membership profile (Kaufman and Rousseeuw, 1990). In this case, an airport may strongly identify with one particular cluster, but it also may have characteristics that are similar to airports in a second (i.e., different) cluster. This allows for more flexibility in the interpretation of generated typologies and remediates one of the most notable weaknesses in non-hierarchical clustering, hard assignments (Grubesic, 2006). Although space limitations prevent us from detailing the large literature on cluster analysis and its applications, readers are referred to Kaufman and Rousseeuw (1990) for an excellent review on statistical clustering, and Murray et al. (2014) for a review of spatial clustering. For details on the fuzzy clustering method used in this paper, please see the Appendix.

\section{RESULTS}

Based on the 2013 DB1B market data, 465 airports $^{9}$ were initially used for analysis. In total, there are 746,398 unique flight itineraries operating between the 465 airports. Further, the entire air traffic network across the United States and its territories consists of 465 airports that provided commercial services in 2013 and includes all FAA-defined large, medium, and small hubs, primary non-hubs, commercial service airports, general aviation airports, EAS airports, and airports awarded SCADSP funding. ${ }^{10}$ Considering all possible flight combinations, the resulting diameter of the DB1B network is eleven and involves a trip from Marshall, Alaska (MLL), to Teller, Alaska (TLA). Without delving into the gory details of the potential itinerary between these two locations, Anchorage (ANC), the largest airport in Alaska, is not a primary hub connecting this O-D pair. Instead, it serves as a subconnection, with a mandatory route via locations in the contiguous 48 states. ${ }^{11}$ When one eliminates these types of unusual itineraries, a more realistic snapshot of network diameter begins to emerge. For instance, when itineraries with 1 or fewer passengers are eliminated, it is possible to book a trip from the Mid-America St. Louis Airport (BLV) to Chefornak, Alaska (CYF), yielding a diameter of six for the network. Thus, although there is a case to be made for removing outliers from the analysis, the sheer

\footnotetext{
${ }^{9}$ Although over 3,300 airports are identified by the FAA's National Plan of Integrated Airport System, 465 airports are identified as having commercial service in the DB1B database in 2013.

${ }^{10}$ Passenger-based and subsidy/grant-based airport categories are not excluded.

${ }^{11}$ It is important to note for readers that the purchase of an eleven-segment itinerary, while possible in the DB1B database, may be extraordinarily difficult for a typical passenger via standard booking engines. Realistically, this is a trip that could never be booked and service between this O-D pair would require a chartered flight.
} 
Figure 2: Rural Airports in the United States with Commercial Traffic, 2013

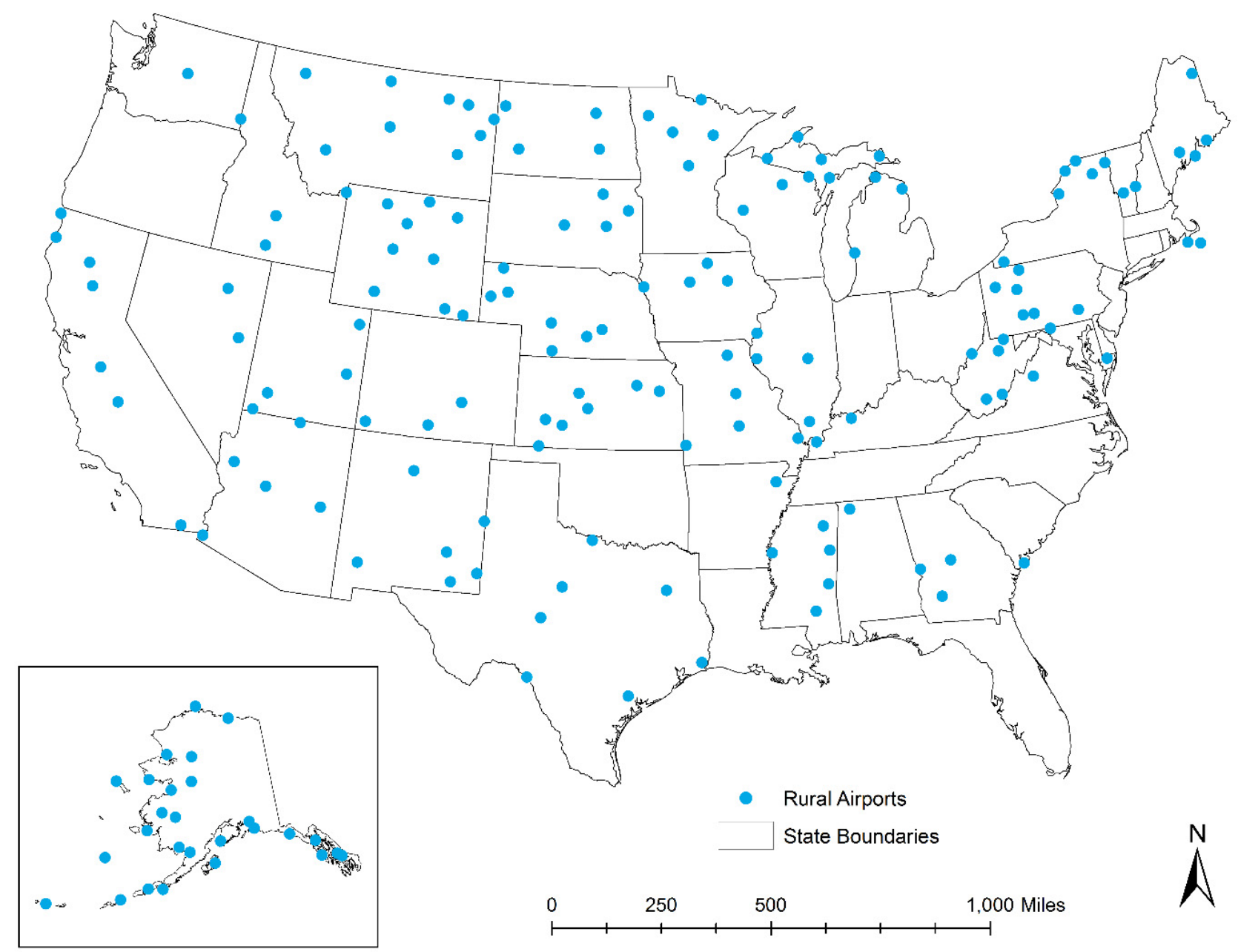

number of itineraries processed in this analysis will effectively smooth the bias generated by the extreme itineraries. Thus, this paper keeps the DB1B data intact for analysis.

\subsection{Rural Markets}

In an effort to deepen our understanding of these smaller airports, we leverage information from the DB1B Market database using the final list of rural airports outlined previously. Figure 2 displays the spatial distribution of 177 rural airports providing commercial air service in the contiguous U.S., its territories, and Alaska in $2013 .^{12}$ It is important to emphasize that although this paper focuses on the subset of 177 rural airports, all network measures are generated using the complete air transport network and the 465 active commercial airports in the U.S.

\footnotetext{
${ }^{12}$ Routes to Hawaii are included in the network analysis, but since Hawaii does not have any rural airports, it is not considered for the rural analysis, nor is it visualized in the associated figures.
} 
Table 2: Top Ten Rural Airports with Passenger and Frequency Counts

\begin{tabular}{lll}
\hline \hline Ranking & Total Number of Passengers & Frequency Counts \\
\hline 1 & Kalispell, MT (FCA) [37,084] & Kalispell, MT (FCA) [28,475] \\
2 & Plattsburgh, NY (PBG) [25,658] & Williston, ND (ISN) $[16,333]$ \\
3 & Williston, ND (ISN) [17,793] & Tyler, TX (TYR) $[15,481]$ \\
4 & Casper, WY (CPR) [16,914] & Abilene, TX (ABI) $[14.032]$ \\
5 & Tyler, TX (TYR) [16,410] & Yuma, AZ (YUM) $[13,733]$ \\
6 & Abilene, TX (ABI) [15,634] & Casper, WY (CPR) $[13,125]$ \\
7 & Yuma, AZ (YUM) [15,486] & Salisbury, MD (SBY) $[11,058]$ \\
8 & Sitka, AK (SIT) [12,197] & Hilton Head Island, SC (HHH) $[10,851]$ \\
9 & Hilton Head Island, SC (HHH) [11,867] & San Angelo, TX (SJT) $[10,752]$ \\
10 & San Angelo, TX (SJT) [11,793] & Manhattan, KS (MHK) $[10,004]$ \\
\hline \hline
\end{tabular}

Table 2 presents the top ten rural airports by passengers and flight frequency. Not only does Kalispell, Montana (FCA), serve the most passengers, it also has the highest frequency of service of any rural airport. To provide some perspective on these results, it is important to note that FCA serves as the commercial air gateway to Glacier National Park, which had 2.19 million visitors in 2013 (NPS, 2013). Because of its geographically remote location, driving to Glacier National Park is not a ready option for many visitors. As a result, flights to FCA are frequent during the summer season, with service provided from Portland (PDX); Los Angeles (LAX); Oakland, California (OAK); Atlanta, Georgia (ATL); and Chicago, Illinois (ORD). When combined with year-round connections to Seattle (SEA), Las Vegas (LAS), Minneapolis (MSP), Salt Lake City (SLC), and Denver (DEN), FCA is the busiest rural airport in the U.S, serving $198,918^{15}$ passengers on 3,225 flights in $2013 .{ }^{16}$

In addition to FCA, many of the top rural airports in enplanements and flight frequency are connected to tourism or fueled by their local economy. For example, Hilton Head Island, South Caroline (HHH), and Yuma, Arizona (YUM), are prime outdoor recreation areas that attract large numbers of "snowbirds" who seek refuge from the north's harsh winters. Williston, North Dakota (ISN), is a central point in the Williston Basin and associated Bakken formation, which is currently producing more oil than other region in the United States (EIA, 2013) and generating significantly more demand for air travel to and from the region.

When compared to enplanements and flight frequency metrics, a network analysis of the air transport system for the U.S. generates a similar list of rural airports. Figure 3 and Table 3 detail these results. FCA has the smallest Shimbel distance $(1,095)$, which suggests that there are 1,095

\footnotetext{
${ }^{13}$ This is the total count of passengers served from the DB1B sample (10\%).

${ }^{14}$ This is the total count/frequency of scheduled and non-scheduled flights (arrival and departure) from the DB1B sample (10\%).

15191,918 is the actual number of passengers for all scheduled services in 2013 at FCA. Information was obtained from http://www.transtats.bts.gov/Data_Elements.aspx?Data=1.

${ }^{16}$ These regular and semi-regular connections do not include infrequent charter flights which can appear as in the DB1B database for certain city pairs, especially in resort areas.
} 
steps required to connect Kalispell to the other 464 commercial airports in the U.S. This suggests that Kalispell is the most accessible rural airport in the country. This is not a surprising result, given all the larger hubs that connect to FCA (e.g. LAX, SEA, ORD, etc). Joplin, Missouri (JLN), has the second-lowest $D$ measure $(1,157)$ and Casper, Wyoming $(\mathrm{CPR})$, is a close third, requiring 13 additional steps. Of note is that Joplin is an EAS community and currently served by American Eagle with a connection to DFW during 2013. ${ }^{17}$ Again, this singular connection to DFW is the primary driver of a low $D$ value. Unlike JLN, CPR is able to maintain commercial air services without EAS subsidies, but it did receive a SCASDP grant in 2012. $\$ 100,000$ in federal funds was provided to the Casper airport, with an additional $\$ 70,000$ of in-kind contributions from other local entities. These monies were dedicated to marketing efforts to enhance service on the CPR-LAS connection, support new service between CPR and SLC, and address high fare issues for the airport (CNCIA, 2012).

\section{Figure 3: Shimbel Index of Rural Airports in the United States, 2013}

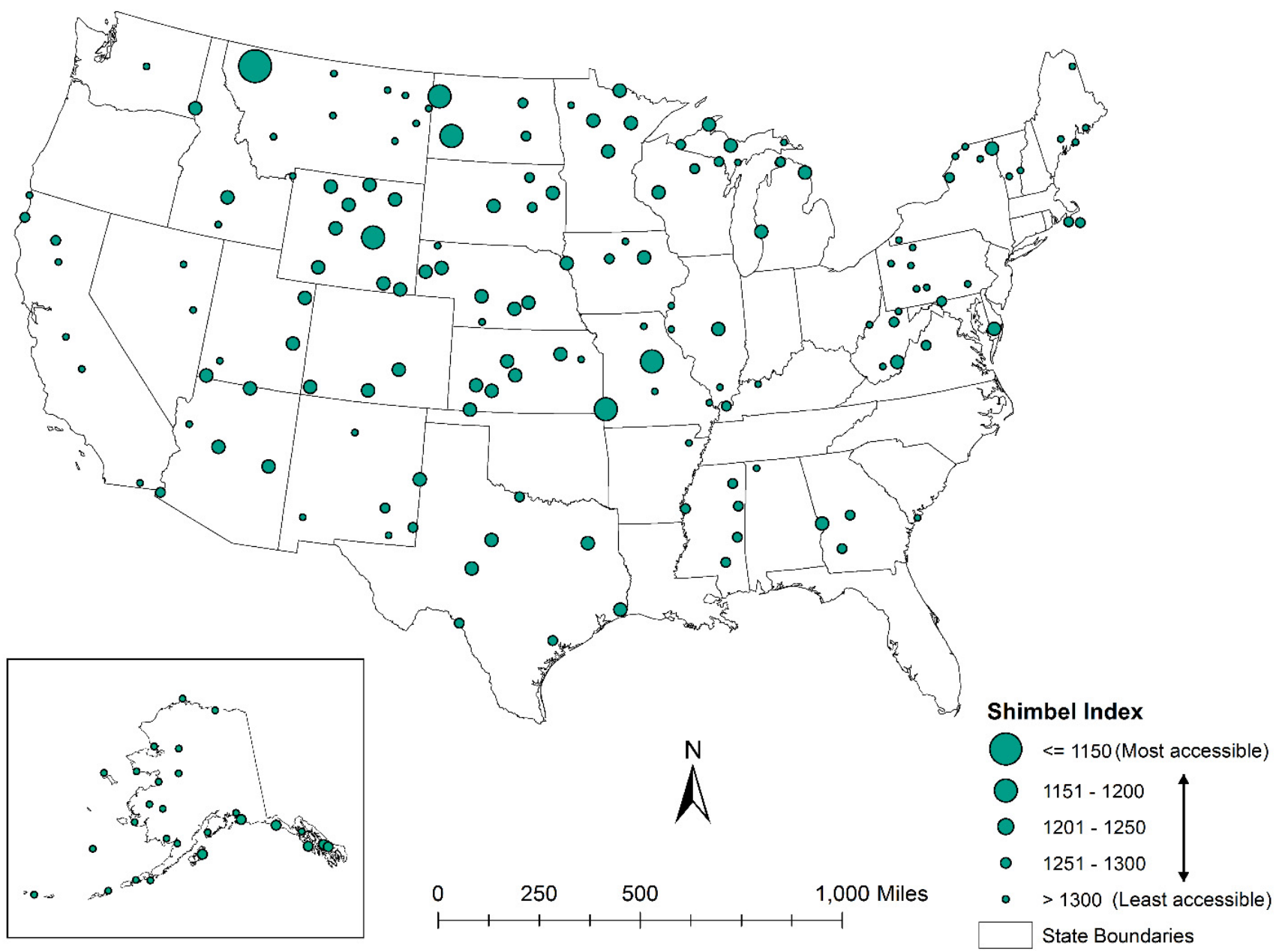

\footnotetext{
${ }^{17}$ This route is served by a 50-seat Embraer ERJ aircraft and has the lowest EAS subsidy rate in the system (\$342,560) (USDOT, 2013d).
} 
Table 3: Top Ten Rural Airports with the Shortest Shimbel Distance

\begin{tabular}{lll}
\hline \hline Ranking & Airport & Shimbel Distance \\
\hline 1 & Kalispell, MT (FCA) & 1095 \\
2 & Joplin, MO (JLN) & 1157 \\
3 & Casper, WY (CPR) & 1170 \\
4 & Columbia, MO (COU) & 1178 \\
5 & Williston, ND (ISN) & 1198 \\
6 & Dickinson, ND (DIK) & 1199 \\
7 & Manhattan, KS (MHK) & 1206 \\
8 & Pueblo, CO (PUB) & 1206 \\
9 & Grand Island, NE (GRI) & 1207 \\
10 & Beaumont/Port Arthur, TX (BPT) & 1208 \\
\hline \hline
\end{tabular}

At the opposite end of the spectrum are the most poorly connected airports, such as Marshall, Alaska (MLL) (3,474 steps), Unalakleet, Alaska (UNK) (2,837 steps), Lewistown, Montana (LWT) (2,738 steps), and Ely, Nevada (ELY) (2,260 steps). Located on the Norton Sound of the Bering Sea, Unalakleet is one of the most remote places in Alaska. It is primatily a cargo airport, although 13,430 passengers did use commercial air service during $2013 .{ }^{18}$ The issues associated with connectivity and EAS subsidies for Lewistown have been documented thoroughly in the literature (Grubesic and Matisziw, 2011; Matisziw et al., 2012; Grubesic et al., 2012), so its low ranking is not surprising. In fact, LWT is no longer served by an EAS carrier because the subsidies per passenger exceeded the $\$ 1,000$ limit. Ely, Neveda, a former EAS community, lost commercial service because, at $\$ 3,720$ per passenger, it too exceeded the federally mandated per passenger subsidy maximum of $\$ 1,000$.

Table 4 lists the rural airports with the highest centrality measures. Figures 4, 5, and 6 enable visualizations of the degree, closeness, and betweenness measures of rural airports in the United States, respectively. It is important to place these results in context (see Table 4), however. Once again, consider FCA, which appears near the top of the list for degree and closeness, but note it does not register highly for betweenness, suggesting that it is a true origindestination (i.e., start point/endpoint) in the network with no hub functionality. Even Plattsburgh, New York (PBG), which leads all rural airports in betweenness, does not truly function as a hub in any case, but does offer service to Fort Lauderdale (FLL), Fort Myers (RSW), Seaford (SFB), Clearwater (PIE) (all in Florida), Boston, Massachusetts (BOS), and has seasonal flights to Myrtle Beach, South Carolina (MYR). Since it is close to the Canadian border PGB serves is a gateway to Canadian shoppers especially a connecting point for their travel to Florida. In short, there is variety in the centrality measures for rural locations, all of which is fueled by operational quirks (e.g. EAS connections to hubs) or network geographic context (central locations in the U.S.).

${ }^{18}$ UNK has a direct connection to both Anchorage and Nome. 
Table 4: Top Ten Rural Airports and Associated Measures of Centrality

\begin{tabular}{|c|c|c|c|c|c|c|}
\hline Ranking & Airport & Degree & Airport & Closeness & Airport & Betweenness \\
\hline 1 & $\begin{array}{l}\text { Kalispell, MT } \\
\text { (FCA) }\end{array}$ & 19 & $\begin{array}{l}\text { Kalispell, } \\
\text { MT (FCA) }\end{array}$ & 0.428440 & $\begin{array}{l}\text { Plattsburgh, NY } \\
\text { (PBG) }\end{array}$ & 0.000134 \\
\hline 2 & $\begin{array}{l}\text { Yuma, AZ } \\
\text { (YUM) }\end{array}$ & 17 & $\begin{array}{l}\text { Casper, WY } \\
\text { (CPR) }\end{array}$ & 0.403829 & $\begin{array}{l}\text { Manhattan, KS } \\
\text { (MHK) }\end{array}$ & 0.000085 \\
\hline 3 & $\begin{array}{l}\text { Casper, WY } \\
\text { (CPR) }\end{array}$ & 15 & $\begin{array}{l}\text { Joplin, MO } \\
\text { (JLN) }\end{array}$ & 0.403829 & $\begin{array}{l}\text { Lewiston, ID } \\
\text { (LWS) }\end{array}$ & 0.000066 \\
\hline 4 & $\begin{array}{l}\text { Nantucket, } \\
\text { MA (ACK) }\end{array}$ & 15 & $\begin{array}{l}\text { Williston, } \\
\text { ND (ISN) }\end{array}$ & 0.402080 & $\begin{array}{l}\text { Rock Springs, } \\
\text { WY (RKS) }\end{array}$ & 0.000049 \\
\hline 5 & $\begin{array}{l}\text { Plattsburgh, } \\
\text { NY (PBG) }\end{array}$ & 14 & $\begin{array}{l}\text { Columbia, } \\
\text { MO (COU) }\end{array}$ & 0.396581 & $\begin{array}{l}\text { Nantucket, MA } \\
\text { (ACK) }\end{array}$ & 0.000047 \\
\hline 6 & $\begin{array}{l}\text { Vineyard } \\
\text { Haven, MA } \\
\text { (MVY) }\end{array}$ & 11 & $\begin{array}{l}\text { Cody, WY } \\
\text { (COD) }\end{array}$ & 0.389916 & $\begin{array}{l}\text { Yuma, AZ } \\
\text { (YUM) }\end{array}$ & 0.000035 \\
\hline 7 & $\begin{array}{l}\text { Petersburg, } \\
\text { AK (PSG) }\end{array}$ & 10 & $\begin{array}{l}\text { Dickinson, } \\
\text { ND (DIK) }\end{array}$ & 0.389916 & $\begin{array}{l}\text { Casper, WY } \\
(\mathrm{CPR})\end{array}$ & 0.000033 \\
\hline 8 & $\begin{array}{l}\text { Wrangell, AK } \\
\text { (WRG) }\end{array}$ & 10 & $\begin{array}{l}\text { Pierre, SD } \\
\text { (PIR) }\end{array}$ & 0.389916 & $\begin{array}{l}\text { Columbus, GA } \\
\text { (CSG) }\end{array}$ & 0.000027 \\
\hline 9 & $\begin{array}{l}\text { Lewiston, ID } \\
\text { (LWS) }\end{array}$ & 9 & $\begin{array}{l}\text { Pueblo, CO } \\
\text { (PUB) }\end{array}$ & 0.387960 & $\begin{array}{l}\text { Salisbury, MD } \\
\text { (SBY) }\end{array}$ & 0.000024 \\
\hline 10 & $\begin{array}{l}\text { Sitka, AK } \\
\text { (SIT) }\end{array}$ & 9 & $\begin{array}{l}\text { Manhattan, } \\
\text { KS (MHK) }\end{array}$ & 0.387312 & $\begin{array}{l}\text { Clarksburg, WV } \\
\text { (CKB) }\end{array}$ & 0.000022 \\
\hline
\end{tabular}

Figure 4: Degree Measure of Rural Airports in the United States, 2013

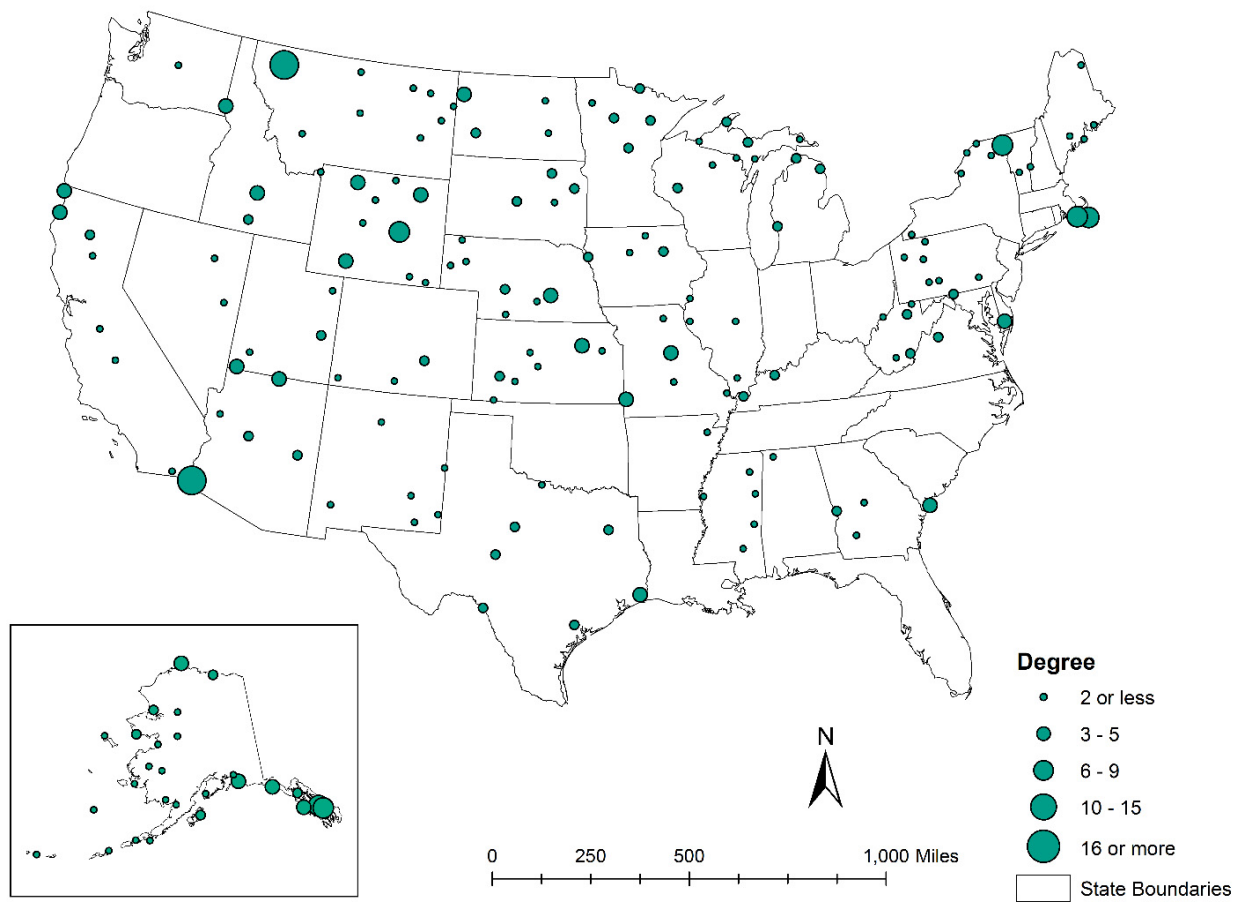

(C) Southern Regional Science Association 2015. 
Figure 5: Closeness Measure of Rural Airports in the United States, 2013

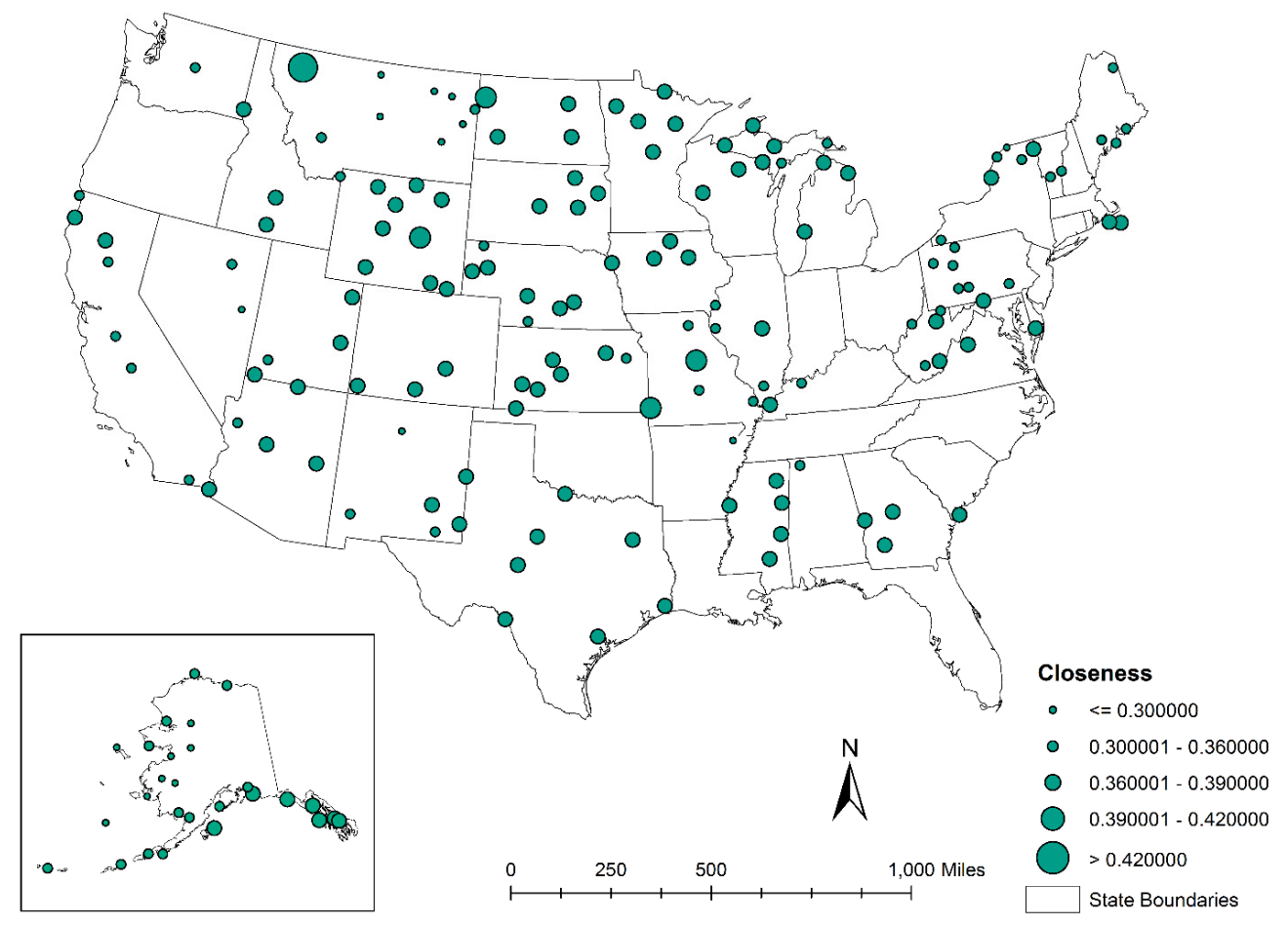

Figure 6: Betweenness Measure of Rural Airports in the United States, 2013

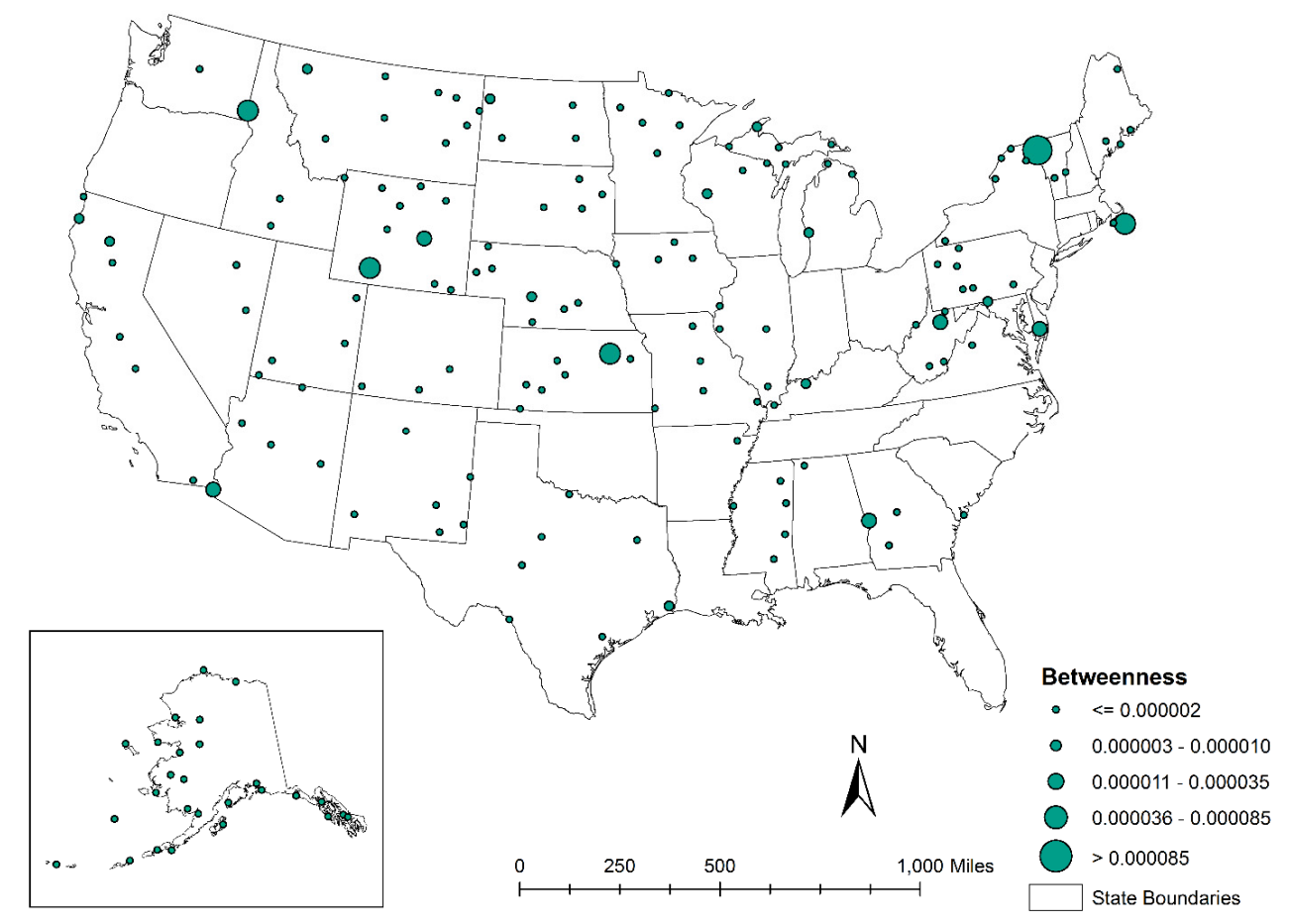

(C) Southern Regional Science Association 2015. 


\subsection{Rural Airport Peer Groups}

We use cluster analysis to disentangle twelve measures of the derived network, data on passengers, market fares, miles flown, and frequency of service for rural airports. The result is a typology of airports and a delineation of rural airport into peer groups. Table 5 presents the averages of those variables at the national level and the three derived clusters. In addition, it is important to note that the four key attributes associated with air traffic flow have two facets each: origin-side and destination-side metrics. For example, consider the airport pair of FCA and SEA. There is a market fare associated with each airport (both origin and destination) and these fares are not necessarily identical. The fare from SEA to FCA may be more expensive than the fare from FCA to SEA. Thus, both sides of the market fare, for all interacting pairs, are considered for each airport in the cluster analysis. In addition, where the process of clustering is concerned, since fuzzy approaches are a generalization of partition-based approaches, it is necessary to predefine the number of clusters $(k)$ for analysis. Rather than simply picking a static value for $k$, however, we use a range of values $(k=3,4, \ldots, 15)$ to determine the sensitivity of the peer group definitions. A suite of diagnostic metrics were also used to make final classifications, including silhouette coefficients for evaluating the quality of the cluster results.

When the average silhouettes were evaluated for each $k$, the highest value was 0.493 for $k=3$. As a result, three clusters were generated to define rural airport peer groups and each airport was assigned to the cluster corresponding with its highest probability score. The following are the details of each of the three cluster groups and the associated rural airport typology:

Table 5: Summary Statistics of Clusters for Rural Airports

\begin{tabular}{lrrrr}
\hline \hline & $\begin{array}{c}\text { Rural } \\
\text { National } \\
\text { Average }\end{array}$ & $\begin{array}{c}\text { Cluster 1: } \\
\text { Rural } \\
\text { Overachievers }\end{array}$ & $\begin{array}{c}\text { Cluster 2: } \\
\text { Middling Rural } \\
\text { Gateways }\end{array}$ & $\begin{array}{c}\text { Cluster 3: } \\
\text { Moribund Rural } \\
\text { Terminals }\end{array}$ \\
\hline Passengers (Departure) & 1,638 & 6,379 & 1,990 & 261 \\
Passengers (Arrival) & 1,640 & 6,357 & 2,014 & 271 \\
Market Fares ${ }^{19}$ (Departure) & $\$ 378.33$ & $\$ 354.77$ & $\$ 385.31$ & $\$ 380.98$ \\
Market Fares (Arrival) & $\$ 388.97$ & $\$ 358.81$ & $\$ 398.03$ & $\$ 392.27$ \\
Miles Flown (Departure) & $1,732.81$ & $1,756.22$ & $1,933.56$ & $1,630.41$ \\
Miles Flown (Arrival) & $1,739.12$ & $1,749.21$ & $1,929.08$ & $1,646.19$ \\
Frequency Counts (Departure) & 1,292 & 4,907 & 1,571 & 236 \\
Frequency Counts (Arrival) & 1,298 & 4,926 & 1,582 & 247 \\
Degree & 3.7 & 7.730769 & 4.020408 & 2.231707 \\
Closeness & 0.352224 & 0.381053 & 0.365503 & 0.338629 \\
Betweenness & $3.32 \mathrm{E}-06$ & 0.000018 & $1.64 \mathrm{E}-06$ & $3.71 \mathrm{E}-07$ \\
Shimbel & 1,364 & 1,235 & 1,289 & 1,432 \\
Cluster Size & 177 & 26 & 49 & 102 \\
EAS Airports & 106 & 2 & 24 & 80 \\
EAS (AK) Airports & 6 & 0 & 3 & 3 \\
SCASDP Airports & 12 & 5 & 4 & 3 \\
\hline \hline
\end{tabular}

${ }^{19}$ Market fares are for one-way segments. 
Figure 7: The Spatial Distribution of Rural Airport Cluster Groups in the United States, 2013

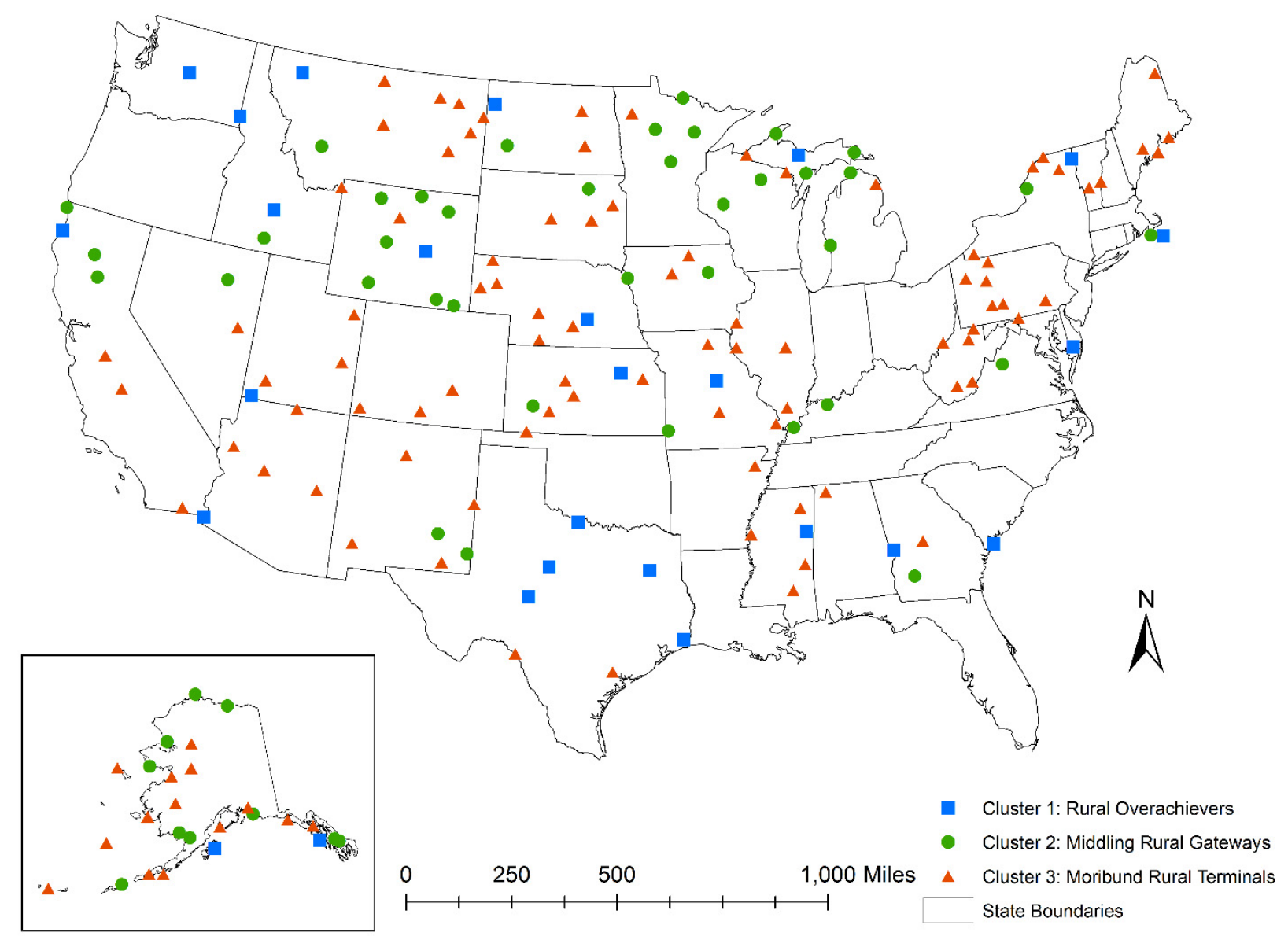

Cluster 1: Rural Overachievers

The Rural Overachievers group is the smallest of the three clusters with 26 member airports (see Table 5 and Figure 7). Representative members include FCA, CPR, and PBG. Perhaps the most notable characteristic of this group is the high volume of passenger arrivals and departures, both of which average over 6,300 per year. This is much higher than the national average for rural airports. Interestingly, the listed fares associated with these airports are the lowest, on average, between the three groups, even if the miles-flown are somewhat higher than Cluster 3. Frequency of service for the Rural Overachievers is also significantly higher than the other groups, as is the degree of node for these airports. Perhaps the biggest surprise for this group is that two members-PBG and Grand Island, Nebraska (GRI) - are EAS subsidized. The nuances of PBG were discussed earlier, but GRI is an interesting market. EAS currently subsidizes the GRI to DFW route via American Eagle for $\$ 2.2$ million per year, however, Allegiant Air has also moved into the market. It offers connections to Mesa, Arizona (AZA), and LAS. In previous work, Grubesic and Wei (2013) note that GRI does not lie within the air traffic shadow of a larger metropolitan area (Taaffe, 1956), which helps GRI maintain a somewhat captive commercial passenger market. The economy is also vibrant in Grand Island, largely focused on agribusiness, which spurs additional demand for commercial service (Grubesic and 
Wei, 2013). ${ }^{20}$ Finally, five of the Rural Overachiever airports received SCASDP grants between 2011 and 2013, including Hailey, Idaho (SUN); ${ }^{21}$ San Angelo, Texas (SJT); St. George, Utah (SGU); Wenatchee, Washington (EAT), and CPR.

\section{Cluster 2: Middling Rural Gateways}

The Middling Rural Gateways group is an interesting mix of 49 airports from the contiguous U.S. and Alaska, but it also includes Pago Pago (PPG), which is located on American Samoa, an unincorporated U.S. territory in the South Pacific. Other representative airports include Barrow, Alaska (BRW); Redding, California (RDD); and Laramie, Wyoming (LAR). Of note is that 24 non-Alaska EAS communities are included in this cluster. This means that almost half of the airports in this group require subsidies to maintain commercial service. This cluster has the highest market fare, on average $(\sim 390)$, and trip distances in this group are the longest of all three clusters, averaging over 1,900 miles. In part, this can be attributed to the presence of PPG, where the only jet service available is to HNL, 2,613 miles away. Where the centrality measures are concerned, the average degree of node (4.02) is slightly higher than the national average (3.7), but many of these airports (including most of the EAS communities) only maintain one commercial connection. For example, the only commercial service available to and from RDD is to San Francisco (SFO) via United Express (SkyWest). RDD is not alone; many nonEAS airports are only able to support a single connection in this group, such as LAR-DEN and Twin Falls, Idaho (TWF-SLC). There are other airports in this group that support more connections, increasing the average degree of node measure for the cluster. For example, Vineyard Haven, Massachusetts (MVY), maintains service to BOS, Nantucket, Massachusetts (ACK); and New Bedford, Massachusetts (EWB), with seasonal service to JFK (New York, New York); White Plains, New York (HPN); Teterboro, New Jersey(TEB); and Arlington, Virginia (DCA). Also, while many of the airports in Alaska included in this group (Petersburg [PSG], Wrangell [WRG], Cordova [CDV], etc.) maintain multiple connections via Alaska Airlines, other airports in this cluster benefit from semi-frequent charter services when permanent commercial connections are unavailable.

\section{Cluster 3: Moribund Rural Terminals}

The final group of 102 airports is Moribund Rural Terminals, which includes 80 nonAlaska EAS communities. Representative locations include Muscle Shoals, Alabama (MSL); Jonesboro, Arkansas (JBR); Miles City, Montana (MLS); and LWT. Commercial service in these communities is sparse, with only several hundred passengers departing or arriving, on average, during 2013..$^{22}$ Although the market fares correspond to the national benchmarks for rural airports, it is important to remember that EAS subsidies reduce the fare burden for passengers, keeping them artificially low and relatively close to the rural averages. The true cost of operating these flights is very high and if portions of these expenses were passed on to customers through

\footnotetext{
${ }^{20}$ During the recent U.S. recession (2007-2009), Grand Island's economy was relatively resistant to the economic downturn. With an emphasis on agriculture and agricultural equipment production, unemployment rates remained low and factories were working at capacity (Gandel, 2011).

${ }^{21}$ SUN won a SCASDP award to explore the expansion of commercial air service from a large hub in the eastern U.S. (e.g., Cleveland, Columbus, Washington, New York City) to Hailey, Idaho. The plan is to attract more tourism dollars to the region during ski season (FMAA, 2013).

${ }^{22}$ Some rural airports may survive as centers for cargo transport or landing facilities but they do not provide any access to the national transportation network for passengers, a primary factor that keeps airports operating and maintains/develops local economic activities. Lack of passenger traffic is not only an important factor affecting rural airports, but also rural communities in general.
} 
the fares, the ticket prices would increase dramatically. Further, it is likely that there would be no commercial service for the majority of these cities without the EAS program (Grubesic et al., 2014). Perhaps the most revealing statistic is the average $D$ measure $(1,432)$ for these locations. This suggests that, on average, the Moribund Rural Terminals require 143 more steps than Middling Rural Gateways and 197 more steps than Rural Overachievers to connect to all of the commercial airports in the U.S. This underscores exactly how remote and poorly served this cluster is, even when compared to their rural peers. For example, consider Topeka, Kansas (FOE), the state capital and home to a metropolitan area population of over 234,000. In 2013, only a handful of commercial flights operated to and from FOE according to the T-100 database. ${ }^{23}$ Specifically, there are twenty destinations connecting to FOE with commercial and non-commercial scheduled service. For example, three charter flights between FOE and Laughlin/Bullhead City, Arizona (IFP), were documented, all of which were operated by Sun Country Airlines and all passengers were destined for Don Laughlin's Riverside Resort in Laughlin, Nevada. Unlike GRI, detailed previously, FOE is located within the shadow of a much larger metropolitan area and its airport (77 miles from Kansas City, Missouri [MCI]). This clearly presents challenges in attracting regular commercial service. However, this is exactly what happened in January 2014, when United Airlines began offering multiple daily roundtrips between FOE and ORD. Unfortunately, United cancelled this service only 6 months later because, on average, only 49 percent of the available seats were filled for this route, much lower than the average of 86 percent for United's other Chicago routes and the third lowest for all flight segments in United Airline's network (Schleisman and Dulle, 2014). Today, once again, the only commercial service in/out of FOE is a charter flight to Wendover, Utah (ENV), or Laughlin-Bullhead (IFP), offered every 6 weeks from Allegiant Air. FOE is not unique; many of the Moribund Rural Terminals are currently served by infrequent charter flights and remain without regular commercial air transport service.

\subsection{Transitory Peers}

A final group worth mentioning includes the transitory airports which have a relatively equal probability of membership across multiple clusters. From a statistical perspective, although these airports are correctly assigned to their optimal peer group, there is statistical evidence that they also identify with airports in a different cluster. For example, consider Southwest Georgia Regional Airport (ABY), located in Albany, Georgia, which is a member of the Middling Rural Gateways cluster. ABY is located about 175 miles south of Atlanta and 75 miles north of Tallahassee, Florida. The probability of ABY's membership to Middling Rural Gateways is moderate, at 45.01 percent (Table 6). However, it also has a 37.11 percent probability of belonging to Rural Overachievers. If one digs a bit deeper into the characteristics associated with ABY, it becomes clear that average market fares $(\sim 360)$ compare quite favorably to the national averages and Rural Overachievers, but the passenger enplanements $(\sim 2,990)$ are lower than the $\sim 6,300$ mark for Rural Overachievers. In other instances, many of the airports that belong to Middling Rural Gateways are also closely related to Moribund Rural Terminals (Table 6). If nothing else, this highlights the razor-thin line between seemingly viable rural airports and those that are struggling. It also highlights potential pathways for middling airports to achieve more success. For example, can issues of low enplanements be addressed for airports like Albany,

\footnotetext{
${ }^{23}$ The T-100 database provides a 100 percent census of the domestic and international air traffic data. It provides monthly traffic and operational data for each carrier and for each city-pair market that the carrier operated (USDOT, 2013e). However, the T-100 does not provide market fares or itinerary costs, limiting its overall appeal for the analysis in this paper.
} 
Georgia (ABY), helping them break into the Rural Overachievers group? The answer is a definitive yes, particularly if local managers are aspiring to expand airport operations, increase quality of service, and attract more passengers. In fact, this is exactly what SCASDP grants are for. In the next section, we detail how this type of empirical evidence can be used for airport planning and improving rural air transportation policy.

\section{DISCUSSION AND CONCLUSION}

There are several facets of the results worth further discussion. First, many rural airports are struggling to attract passengers, provide competitive fares, and maintain a reasonable frequency of service. 58 percent (102 of 177) of rural airports in this analysis can be considered moribund - exhibiting limited frequency of service, few enplanements, low load factors, ${ }^{24}$ little network connectivity, and an over-reliance on infrequent charter flights. In fact, the vast majority (81 percent) of these moribund airports are part of the Essential Air Service program, relying on subsidies to help maintain their connection to the commercial air network.

As detailed throughout, the EAS program is an interesting one, but not without controversy. As of November 2013, \$219.8 million was allocated to carriers for providing commercial air transport service to 106 communities in the lower 48 states. At the top end of this subsidy spectrum, \$3.8 million was provided to Presque Isle/Houlton, ME (PQI) for connecting

Table 6: List of Transitory Airports

\begin{tabular}{lllccc}
\hline \hline Airport ID & City & State & \multicolumn{3}{c}{ Probabilities } \\
\cline { 3 - 5 } & & $\begin{array}{c}\text { Cluster 1: } \\
\text { Rural } \\
\text { Overachievers }\end{array}$ & $\begin{array}{c}\text { Cluster } 2: \\
\text { Middling Rural } \\
\text { Gateways }\end{array}$ & $\begin{array}{c}\text { Cluster 3: } \\
\text { Moribund Rural } \\
\text { Terminals }\end{array}$ \\
\hline ABY & Albany & GA & 37.11 percent & 45.01 percent & 17.88 percent \\
ANI & Aniak & AK & 15.85 percent & 39.29 percent & 44.87 percent \\
BRW & Barrow & AK & 35.38 percent & 43.84 percent & 20.78 percent \\
CMX & Hancock & MI & 38.48 percent & 44.39 percent & 17.13 percent \\
CYS & Cheyenne & WY & 8.47 percent & 50.39 percent & 41.14 percent \\
DLG & Dillingham & AK & 12.05 percent & 46.06 percent & 41.89 percent \\
EAR & Kearney & NE & 7.50 percent & 45.20 percent & 47.29 percent \\
GAL & Galena & AK & 17.54 percent & 39.76 percent & 42.71 percent \\
GAM & Gambell & AK & 18.05 percent & 39.85 percent & 42.10 percent \\
HOM & Homer & AK & 11.24 percent & 44.13 percent & 44.63 percent \\
INL & International & MN & 8.15 percent & 49.33 percent & 42.52 percent \\
& Falls & & & & \\
MLL & Marshall & AK & 20.29 percent & 39.61 percent & 40.10 percent \\
PIR & Pierre & SD & 7.39 percent & 43.81 percent & 48.79 percent \\
PPG & Pago Pago & AS & 30.34 percent & 39.22 percent & 30.44 percent \\
ROW & Roswell & NM & 41.01 percent & 42.14 percent & 16.85 percent \\
UNK & Unalakleet & AK & 16.63 percent & 39.18 percent & 44.20 percent \\
YAK & Yakutat & AK & 8.88 percent & 44.14 percent & 46.99 percent \\
\hline \hline
\end{tabular}

\footnotetext{
${ }^{24}$ Passenger load factors are a measure of how much passenger carrying capacity is used. Specifically, it tracks the number of passenger miles flown as a percentage of seat miles available.
} 
service. As detailed by Grubesic et al. (2014), the hope is that these communities will eventually generate enough passenger demand and associated traffic to operate without subsidies, but this rarely occurs. Most communities remain subsidized because they are simply too small, too remote, or their market demand is too low to support regular commercial service.

What does this mean for the EAS program and rural communities dependent upon subsidies for commercial air transport? The future is not clear. EAS continues to be criticized for its high costs, low efficiency, and infrequent passenger use throughout the U.S. (Grubesic et al., 2014), but it continues to survive as a program because of many vocal proponents in the U.S. Congress and Senate that represent rural constituencies (Taylor, 2012). In short, with a federal budget request that exceeds \$3.9 trillion for 2015 in the U.S., cutting \$220 million dollars from the EAS program barely registers as a concern. If anything, the potential fiscal savings achieved by cutting EAS would be offset by antagonizing members of Congress who are strong supporters of the program. As a result, EAS perseveres.

On a much smaller scale, the SCASDP program awarded a paltry $\$ 11.4$ million during 2013 and each recipient received less than \$1 million. Unlike EAS, which provides subsidies directly to airlines, SCASDP is designed to encourage small communities to operate sustainably and to mitigate operational challenges through creative problem solving and strategic decisionmaking. This may involve the aggressive pursuit of carriers to provide service to new markets, or to improve advertising efforts within the region. Regardless, it is this type of targeted funding that may help rural and remote communities achieve sustainable commercial service in the long run, helping them avoid any and all dependency associated with the pervasive EAS safety net that has existed since 1978.

In sum, while there are many rural airports that continue to struggle, all is not gloomy. The Rural Overachievers group represents a healthy subset of rural markets that exhibit relatively low average fares when compared to their rural peers, a diverse set of network connections and a relatively high number of annual enplanements when compared to the rural national average. Although each of these markets is different, there are a few commonalities amongst this group. Most of these airports serve relatively captive geographical markets, far removed from the spatial influence or "shadow" of larger hub airports. Again, Grand Island (GRI) is an excellent example of this phenomenon as it is located 153 miles from the nearest major airport in Omaha (OMA). Many Rural Overachievers also have vibrant local economies. In the case of Williston (ISN), the oil industry is booming, generating significant demand for business travel to and from the area. Finally, the best rural markets have an excellent match between supply and demand in the structure of the network serving a community. Although every rural airport authority would like to have multiple connections, more connectivity does not always equate to better service. Too many connections (or frequency of service) means that carriers are running planes with fewer passengers and low load factors. Over time, this reduces profits and may negatively impact carrier sentiment toward a market (e.g., United Airlines in Topeka). Conversely, too few seats and overcrowded planes reduce profits and negatively impact passenger quality of service. As detailed by Kanafani and Abbas (1987), an extensive origindestination survey is an absolute necessity for rural airports, especially for planning purposes regarding network operations.

One option to break this cycle, especially for the many airports that are classified as Middling Rural Gateways and Moribund Rural Terminals is to implement irregular, "nonscheduled" service like charter flights. For example, Page, Arizona (PGA), and Topeka, Kansas 
(FOE), served over 50 percent of their passengers from non-scheduled services during 2013, including various charter services, air taxi, and air tours. Hattiesburg, Mississippi (PIB), and Pueblo, Colorado (PUB), also have large percent of passengers in non-scheduled services.

In general, both EAS and SCASDP can be helpful to rural communities, but these programs are really structured as short-term fixes, and should be treated as such. With that in mind, the typology of rural airports generated in this paper can serve as a foundation for beginning the process of strategically thinning EAS subsidies and better targeting SCASDP funds. For example, as detailed previously, airports in the Rural Overachievers $(n=26)$ group generally have healthy rural markets and most are able to operate without subsidies or grants. However, as of November 2013, Plattsburgh (PBG) and Grand Island (GRI), two airports in this group, were still receiving $\$ 2,470,834$ and $\$ 1,837,021$ from the EAS program, respectively. These airports may be good candidates for strategic reductions in EAS monies given their local market structure. Of course, a more detailed analysis would be required, but nevertheless, the typology provides a good starting point for asking salient questions.

Finally, the empirical work presented in this paper, particularly concerning peer groups, can serve as a powerful tool for enhancing planning and policy for rural air transport. Not only do peer groups allow managers, policy-makers, and airport authorities to better understand how their airport statistics compare to similar markets, peer groups can also provide intelligence as to what steps can be taken to improve local airport services. Once again, airports like Plattsburgh (PBG) provide a good example. At one time, $\mathrm{PBG}$ was served by a single EAS subsidized carrier. Today, both Allegiant Air and Spirit air provide seasonal roundtrip service to multiple destinations in Florida and South Carolina. PBG is also offering free parking to passengers. Airports aspiring to break-out of the vicious cycle of local air service (Kanafani and Abbas, 1987), such as Topeka (FOE), may wish to leverage some of the strategies used by PBG to attract additional carriers and passengers. SCASDA grants are one option for helping this process along. ${ }^{25}$ More rudimentary strategies can also be ascertained from peer group information. For example, a small investment in marketing efforts may be enough for some airports to attract more passengers. However, without knowing the passenger counts and other relevant performance data of peer airports, setting realistic goals and strategies based on peer benchmarks may be difficult to develop.

In closing, rural air transportation in the United States continues to generate a complex web of economic, operational, geographic and policy challenges. Rural communities are diverse and so are their transportation needs. Clearly, a one-size-fits-all strategy for ameliorating the difficulties associated with rural air transport will not work for the U.S., China, Brazil, or any other large and regionally diverse country. The results of this paper, however, provide a good first step in better understanding the challenges at hand, while simultaneously providing planning officials and policy-makers an exploratory data analysis framework for improving decision making and helping craft higher-quality transport legislation. The combination of high-resolution operations data from airports, network analysis approaches, and statistical clustering techniques allow for an extremely detailed snapshot of airports and their associated context. Although there

\footnotetext{
${ }^{25}$ Manhattan, Kansas (MHK), is another regional airport that was aided by the EAS program between 2003 and 2009 . It was eventually eliminated from the EAS roster, however, because it was able to attract a commercial carrier without subsidies in 2009. Further, MHK benefitted from a SCASDP grant in 2010 to maintain this commercial service as it struggled to become established. It also provides free parking and a rewards program to attract passengers. Currently, MHK operates scheduled commercial service to and from Chicago (ORD) and Dallas-Fort Worth (DFW).
} 
is no easy way forward for many of the rural airports profiled in this paper, there is no reason such communities cannot be better prepared for lobbying for additional support or developing strategies for improving their local transportation options.

\section{REFERENCES}

Allroggen, Florian and Robert Malina. (2014) "Do The Regional Growth Effects of Air Transport Differ Among Airports?," Journal of Air Transport Management, 37, 1-4.

Bania, Neil, Paul W. Bauer, and Thomas J. Zlatoper. (1998) "U.S. Air Passenger Service: A Taxonomy of Route Networks, Hub Locations and Competition," Transportation Research Part E, 34, 53-74.

Bowen, John. (2000) "Airline Hubs in Southeast Asia: National Economic Development and Nodal Accessibility," Journal of Transport Geography, 8, 25-41.

Brueckner, Jan K. (2003) "Airline Traffic and Urban Economic Development," Urban Studies, 40, 1455-1469.

Bureau of Transportation Statistics [BTS]. (2011) National Transportation Atlas Databases 2013. Last accessed May 2015 at

http://www.rita.dot.gov/bts/sites/rita.dot.gov.bts/files/publications/national_transportation _atlas_database/2013/points.html.

. (2013) Airline Origin and Destination Survey (DB1B). Last accessed May 2015 at http://www.transtats.bts.gov/DatabaseInfo.asp?DB_ID=125\&DB_Name=Airline percent20Origin percent20and percent20Destination percent20 $\overline{\text { Survey }}$ percent20(DB1B).

Button, Kenneth and Samantha Taylor. (2000) "International Air Transportation and Economic Development," Journal of Air Transport Management, 6, 209-222.

Button, Kenneth and Junyang Yuan. (2013) "Airfreight Transport and Economic Development: An Examination of Causality," Urban Studies, 50, 329-340.

Casper-Natrona County International Airport [CNCIA]. (2012) Airport Receives Small Community Air Service Development (SCASDP) grant. Last accessed May 2015 at http://tinyurl.com/n3jam9k.

Chou, Yue-Hong. (1993) “Airline Deregulation and Nodal Accessibility," Journal of Transport Geography, 1, 36-46.

Debbage, Keith G. (1999) “Air Transportation and Urban-Economic Restructuring: Competitive Advantage in the US Carolinas," Journal of Air Transport Management, 5, 211-221.

Demetsky, Michael J. and Jerry L. Korf. (1980) "Specification of Rapid Transit Access Mode Requirements," Journal of Advanced Transportation, 14.

Derudder, Ben, Frank Witlox, and Peter J. Taylor. (2007) "U.S. Cities in the World City Network: Comparing Their Positions Using Global Origins and Destinations of Airline Passengers," Urban Geography, 28, 74-91.

Drucker, Peter F. (1994) "The Age of Social Transformation," The Atlantic Online, last accessed May 2015 at http://www.theatlantic.com/politics/ecbig/soctrans.htm.

C Southern Regional Science Association 2015. 
Ellis, Raymond H., John C. Bennett, and Paul R. Rassam. (1974) "Approaches for Improving Airport Access," Journal of Transportation Engineering, 100 (Proc. Paper 10737).

Energy Information Administration [EIA]. (2013) North Dakota Oil Production Reaches New High In 2012, Transported by Trucks and Railroads. Last accessed May 2015 at http://www.eia.gov/todayinenergy/detail.cfm?id=10411.

Federal Aviation Administration [FAA]. (2012) Airport Categories. Last accessed May 2015 at http://www.faa.gov/airports/planning_capacity/passenger_allcargo_stats/categories/.

. (2013) Current Aviation Excise Tax Structure. Last accessed May 2015 at http://tinyurl.com/mo7b6jp.

Federal Register. (2012) Qualifying Urban Areas for the 2010 Census. Last accessed May 2015 at https://www.federalregister.gov/articles/2012/03/27/2012-6903/qualifying-urbanareas-for-the-2010-census.

Fleming, Douglas K. and Yehuda Hayuth. (1994) "Spatial Characteristics of Transportation Hubs: Centrality and Intermediacy," Journal of Transport Geography, 2, 3-18.

Flynn, John and Samuel Ratick. (1988) "A Multiobjective Hierarchical Covering Model for the Essential Air Services Program,” Transportation Science, 22, 139-147.

Friedman Municipal Airport Authority [FMAA]. (2013). Friedman Memorial Airport Hailey, Idaho. Last accessed May 2015 at http:/www.iflysun.com/assets/pdfs/airservicestudies/SUN-SCASDP-Application-2013.pdf.

Freeman, Linton C. (1979) "Centrality in Social Networks Conceptual Clarification,” Social Networks, 1, 215-239.

Gandel, Stephen. (2011) "Want to Make More Than a Banker? Become a Farmer!," Time, July 10, last accessed May 2015 at http://tinyurl.com/lr19bmb.

Geurs, Karst T. and Bert Van Wee. (2004) “Accessibility Evaluation of Land-Use and Transport Strategies: Review and Research Directions," Journal of Transport Geography, 12, 127140.

Gillen, David and Tim Hazledine. (2011) "The New Pricing in North American Air Travel Markets: Implications for Competition and Antitrust," Advances in Airline Economics, 3, 55-82.

Glacier Park International Airport. (2014) Major Cities Served. Last accessed May 2015 at http://www.iflyglacier.com/cities-served.html.

Goetz, Andrew R. (2002) "Deregulation, Competition, and Antitrust Implications in the US Airline Industry," Journal of Transport Geography, 10, 1-19.

Goetz, Andrew R. and Christopher J. Sutton. (1997) "The Geography of Deregulation in the US Airline Industry," Annals of the Association of American Geographers, 87, 238-263.

Goetz, Andrew R. and Timothy M. Vowles. (2009) "The Good, the Bad, and the Ugly: 30 Years of US Airline Deregulation," Journal of Transport Geography, 17, 251-263.

Goff, Brian L. (2005) "Estimating Determinants of Passenger Air Service to Small Markets," Urban Studies, 42, 557-565.

C) Southern Regional Science Association 2015. 
Graham, Anne. (2008) Managing Airports: An International Perspective, $3^{\text {rd }}$ ed. Taylor \& Francis: United Kingdom.

Grubesic, Tony H. (2006) "On the Application of Fuzzy Clustering for Crime Hot Spot Detection," Journal of Quantitative Criminology, 22, 77-105.

Grubesic, Tony H. and Timothy C. Matisziw. (2011) "A Spatial Analysis of Air Transport Access and the Essential Air Service Program in the United States," Journal of Transport Geography, 19, 93-105.

. (2012) "World Cities and Airline Networks," The International Handbook of Globalization and World Cities, 97-116.

Grubesic, Tony H., Timothy C. Matisziw, and Alan T. Murray. (2012) "Assessing Geographic Coverage of the Essential Air Service Program," Socio-Economic Planning Sciences, 46, $124-135$.

Grubesic, Tony H., Timothy C. Matisziw, and Matthew A. Zook. (2008) "Global Airline Networks and Nodal Regions," GeoJournal, 71, 53-66.

Grubesic, Tony H., Timothy C. Matisziw, and Matthew A. Zook. (2009) "Spatio-Temporal Fluctuations in the Global Airport Hierarchies," Journal of Transport Geography, 17, 264-275.

Grubesic, Tony H. and Fangwu Wei. (2013) "Essential Air Service: A Local, Geographic Market Perspective," Journal of Transport Geography, 30, 17-25.

Grubesic, Tony H., Ran Wei, Alan T. Murray, and Fangwu Wei. (2014) "Essential Air Service in the United States Exploring Strategies to Enhance Spatial and Operational Efficiencies," International Regional Science Review, Published online before print May 12, 2014, doi: $10.1177 / 1012690214532653$.

Grubesic, Tony and Matthew Zook. (2007) "A Ticket to Ride: Evolving Landscapes of Air Travel Accessibility in the United States," Journal of Transport Geography, 15, 417430.

Guimerà, Roger, Stefano Mossa, Adrian Turtschi, and Luís A. Nunes Amaral. (2005) “The Worldwide Air Transportation Network: Anomalous Centrality, Community Structure, and Cities' Global Roles," Proceedings of the National Academy of Sciences, 102, 77947799.

Hazledine, Tim. (2011) "Legacy Carriers Fight Back: Pricing and Product Differentiation in Modern Airline Marketing," Journal of Air Transport Management, 17, 130-135.

IATA. (2014) IATA Codes. Last accessed May 2015 at https://www.iata.org/services/pages/codes.aspx.

Internal Revenue Service [IRS]. (2013) Communications and Air Transportation Taxes. Last accessed May 2015 at http://www.irs.gov/publications/p510/ch04.html.

Isserman, Andrew M. (2005) "In the National Interest: Defining Rural and Urban Correctly on Research and Public Policy," International Regional Science Review, 28, 465-499.

Johansson, Börje. (1993) "Infrastructure, Accessibility and Economic Growth," International Journal of Transport Economics, 20, 131-156.

(C) Southern Regional Science Association 2015. 
Kanafani, Adib and Mahmoud S. Abbas. (1987) "Local Air Service and Economic Impact of Small Airports," Journal of Transportation Engineering, 113, 42-55.

Kaufman, Leonard and Peter J. Rousseeuw. (1990) Finding Groups in Data: An Introduction to Cluster Analysis. John Wiley: New York.

Keane, Michael J. (1984) "Accessibility and Urban Growth Rates: Evidence for the Irish Urban System," Economic and Social Review, 15, 125-139.

Keeble, David, Peter L. Owens, and Chris Thompson. (1982) "Regional Accessibility and Economic Potential in the European Community," Regional Studies, 16, 419-431.

Mathur, Vijay K. and Sheldon H. Stein. 2005. "Do Amenities Matter in Attracting Knowledge Workers for Regional Economic Development?," Papers in Regional Science, 84, 251269.

Matisziw, Timothy C. and Tony H. Grubesic. (2010) "Evaluating Locational Accessibility to the US Air Transportation System," Transportation Research Part A: Policy and Practice, 44, 710-722.

Matisziw, Timothy C., Chieh-Lung Lee, and Tony H. Grubesic. (2012) "An Analysis of Essential Air Service Structure and Performance," Journal of Air Transport Management, $18,5-11$.

Murray, Alan T. and Tony H. Grubesic. (2002) "Identifying Non-Hierarchical Spatial Clusters," International Journal of Industrial Engineering, 9, 86-95.

Murray, Alan T., Tony H. Grubesic, and Ran Wei. (2014) "Spatially Significant Cluster Detection," Spatial Statistics, 10, 103-116.

Nader, George A. (1981) "The Delineation of a Hierarchy of Nodal Regions by Means of Higher-Order Factor Analysis,” Regional Studies, 15, 475-492.

National Park Service [NPS]. (2013) National Park Service Press Release. Last accessed May 2015 at http://www.nps.gov/news/release.htm?id=1568.

Nystuen, John D. and Michael F. Dacey. (1961) "A Graph Theory Interpretation of Nodal Regions," Papers of the Regional Science Association, 7, 29-42.

O'Kelly, Morton E. (1998) “A Geographer's Analysis of Hub-and-Spoke Networks,” Journal of Transport Geography, 6, 171-186.

Percoco, Marco. (2010) “Airport Activity and Local Development: Evidence from Italy," Urban Studies, 47, 2427-2443.

Rasker, Ray, Patricia H. Gude, Justin A. Gude, and Jeff Van den Noort. (2009) "The Economic Importance of Air Travel in High-Amenity Rural Areas," Journal of Rural Studies, 25, 343-353.

Reed, Wallace E. (1970) "Indirect Connectivity and Hierarchies of Urban Dominance," Annals of the Association of American Geographers, 60, 770-785.

Redondi, Renato, Paolo Malighetti, and Stefano Paleari. (2013) "European Connectivity: The Role Played by Small Airports," Journal of Transport Geography, 29, 86-94. 
Reynolds-Feighan, Aisling J. (1995) "European and American Approaches to Air Transport Liberalisation: Some Implications for Small Communities," Transportation Research Part A, 29, 467-483.

. (2007) "Competing Networks, Spatial and Industrial Concentration in the US Airline Industry," Spatial and Economic Analysis, 2, 237-257.

Reynolds-Feighan, Aisling and Peter McLay. (2006) "Accessibility and Attractiveness of European Airports: A Simple Small Community Perspective," Journal of Air Transport Management, 12, 313-323.

Schleisman, Nicolette and Brian Dulle. (2014) "United Airlines to End Topeka Service," KSNT.com, last accessed May 2015 at http://ksnt.com/2014/07/23/united-airlines-to-endservices-at-topeka-airport/.

Shaw, Shih-Lung and Russell L. Ivy. (1994) "Airline Mergers and their Effect on Network Structure," Journal of Transport Geography, 2, 234-246.

Taaffe, Edward J. (1956) "Air Transportation and United States Urban Distribution," Geographical Review, 46, 219-238.

Taylor, Andrew. (2012) "House Rejects Bid to Slash Rural Airline Subsidies," cnsnews.com, last accessed May 2015 at http://cnsnews.com/news/article/house-rejects-bid-slash-ruralairline-subsidies.

United States Department of Transportation [USDOT]. (2013a) Small Community Air Service Development Program. Last accessed May 2015 at http://www.dot.gov/sites/dot.dev/files/docs/FY2013_SCASDP_RFP.pdf.

(2013b) Small Community Air Service Development Program (SCASDP). Last accessed May 2015 at http://www.dot.gov/policy/aviation-policy/small-community-rural-airservice/SCASDP.

. (2013c) Rural Airports. Last accessed May 2015 at

http://www.rita.dot.gov/bts/sites/rita.dot.gov.bts/files/subject_areas/airline_information/rural_airp orts/index.html.

. (2013d) Essential Air Service Reports. Last accessed May 2015 at

http://www.dot.gov/office-policy/aviation-policy/essential-air-service-reports.

.. (2013e) Form 41, Schedules T100 and T100(f) Air Carrier Data. Last accessed May 2015

http://2bts.rita.dot.gov/programs/statistical_policy_and_research/source_and_accuracy_c ompendium/form41_schedule.html.

U.S. Bureau of the Census. (2010) 2010 Census Urban and Rural Classification and Urban Area Criteria. Last accessed May 2015 at http:/www.census.gov/geo/reference/ua/urbanrural-2010.html.

van den Heuvel, Frank P., Liliana Rivera, Karel H. van Donselaar, Ad de Jong, Yossi Sheffi, Peter W. de Langen, and Jan C. Fransoo. (2014) "Relationship between Freight Accessibility and Logistics Employment in US Counties," Transportation Research Part A: Policy and Practice, 59, 91-105. 
Vowles, Timothy M. (1999) "Predicting the Loss of Commuter Air Service in the United States," Journal of Air Transport Management, 5, 13-20.

. (2000) "The Effect of Low-Fare Air Carriers on Airfares in the U.S.," Journal of Transport Geography, 8, 121-128.

Wacht, Walter F. (1974) "The Domestic Air Transportation Network of the United States," University of Chicago, Department of Geography.

Wang, Jiaoe, Huihui Mo, and Fahui Wang. (2014) "Evolution of Air Transport Network of China 1930-2012," Journal of Transport Geography, 40, 145-158.

Wittman, Michael D. (2014) "Public Funding of Airport Incentives in the United States: The Efficacy of the Small Community Air Service Development Grant Program," Journal of Transport Policy, 35, 220-228.

Wittman, Michael D. and William S. Swelbar. (2013) "Trends and Market Forces Shaping Small Community Air Service in the United States," MIT International Center for Air Transportation Report No. ICAT-2013-02.

Zhang, Shengrun, Ben Derudder, and Frank Witlox. (2013) "The Impact of Hub Hierarchy and Market Competition on Airfare Pricing in US Hub-to-Hub Markets," Journal of Air Transport Management, 32, 65-70.

Zook, Matthew A. and Stanley D. Brunn. (2006) "From Podes to Antipodes: Positionalities And Global Airline Geographies," Annals of the Association of American Geographers, 96, 471-490.

\section{APPENDIX}

Fuzzy Clustering Problem (FCP)

(1) Minimize $\sum_{c=1}^{k} \frac{\sum_{i=1}^{n} \sum_{j=1}^{n} u_{i c}^{r} u_{j c}^{r} d(i, j)}{2 \sum_{j=1}^{n} u_{j c}^{r}}$

Subject to

(2) $\sum_{c=1}^{k} u_{i c}=1$ for all $i$

(3) $u_{i c} \geq 0$ for all $i$ and $k$

$i, j=$ index of observations;

$n=$ number of observations;

$k=$ number of clusters;

$r=$ membership exponent

$d(i, j)=$ distance between observations $i$ and $j$;

$u_{i k}=$ membership of observation $i$ in cluster $k$.

Fuzzy clustering aims to minimize the objective function (1). Furthermore, the objective function is to minimize the distance between observations $i$ and $j$. The $d(i, j)$ can be calculated as Euclidean, Manhattan, or Squared Euclidean distance. Membership exponent $r$ ranges from 1 to 
$\infty$. When its value is closing to 1 , the clustering result can be converged slowly; when its value is closing to $\infty$, the clustering result can be completely fuzziness (Kaufman and Rousseeuw, 1990). $r=2$ is usually used for fuzzy clustering problem. Constraint (2) indicates that a constant total membership of each observation is spread out over various clusters and constraint (3) identifies non-negativity of membership (Grubesic, 2006). Membership coefficients of an observation can be considered as possibilities of belonging to various clusters. 